San Jose State University

SJSU ScholarWorks

Master's Theses

Master's Theses and Graduate Research

Fall 2017

\title{
The Sediment Analysis of a Prehistoric Shell Midden From Nevis, West Indies
}

\author{
Erika Harvey \\ San Jose State University
}

Follow this and additional works at: https://scholarworks.sjsu.edu/etd_theses

\section{Recommended Citation}

Harvey, Erika, "The Sediment Analysis of a Prehistoric Shell Midden From Nevis, West Indies" (2017). Master's Theses. 4878.

DOI: https://doi.org/10.31979/etd.53kt-4z7d

https://scholarworks.sjsu.edu/etd_theses/4878

This Thesis is brought to you for free and open access by the Master's Theses and Graduate Research at SJSU ScholarWorks. It has been accepted for inclusion in Master's Theses by an authorized administrator of SJSU ScholarWorks. For more information, please contact scholarworks@sjsu.edu. 
THE SEDIMENT ANALYSIS OF A PREHISTORIC SHELL MIDDEN FROM NEVIS, WEST INDIES

\author{
A Thesis \\ Presented to \\ The Faculty of the Department of Applied Anthropology \\ San José State University
}

\author{
In Partial Fulfillment \\ of the Requirements for the Degree \\ Master of Arts
}

by

Erika A. Harvey

December 2017 
(C) 2017

Erika A. Harvey

ALL RIGHTS RESERVED 
The Designated Thesis Committee Approves the Thesis Titled

THE SEDIMENT ANALYSIS OF PREHISTORIC SHELL MIDDEN FROM NEVIS, WEST INDIES

by

Erika A. Harvey

APPROVED FOR THE DEPARTMENT OF APPLIED ANTHROPOLOGY

SAN JOSÉ STATE UNIVERSITY

December 2017

Marco Meniketti, Ph.D. Department of Anthropology

A.J. Faas, Ph.D. Department of Anthropology

Jonathan P. Karpf, Ph.D. ABD Department of Anthropology 


\section{ABSTRACT \\ THE SEDIMENT ANALYSIS OF PREHISTORIC SHELL MIDDEN FROM NEVIS, WEST INDIES \\ by Erika A. Harvey}

Archaeology in the Caribbean is a growing area of research. The last few decades have revealed a series of Ceramic Age sites $\pm 600 \mathrm{BCE}-1620 \mathrm{CE}$ along the Windward coast of Nevis, West Indies. These sites must be excavated and examined soon, due to the effects of erosion and sea level rise. It is pertinent to explore and expand the knowledge of the prehistoric Carib peoples, if we are truly going to understand the history of the Caribbean. By bridging aspects of science and humanities through geoarchaeological methods, this project is aiming for an interdisciplinary approach to better understand the pre-Colonial environment of Nevis. Future researchers could apply these synthesized data to better inform their projects, as archaeologists continue to unravel the history of Prehistoric Caribbean life. The primary objectives of this research were to investigate soil composition, survey landscapes surrounding a midden site, and provide necessary evidence to interpret a relationship between cultures of preindustrial Nevis and their environments. Through sediment and soil analysis, it has been determined there were significant environmental changes from Horizon 2 to Horizon 1, due to the change in color and differing amounts of fine sediment from one horizon to the next. However, further pedology analysis must be conducted for more specific information regarding mineralogy and age of the soil. 


\section{TABLE OF CONTENTS}

List of Tables............................................................... vii

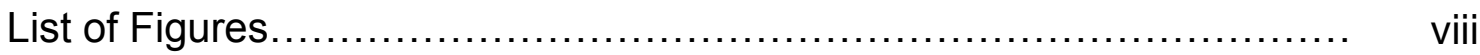

Chapter 1: Introduction................................................. 1

Nevis, West Indies................................................ 3

San Jose State University Nevis Field School $2016 \ldots \ldots \ldots \ldots \ldots \ldots \ldots . . \ldots$

Research Questions.................................................. 6

Nevis Research and Organization of This Thesis...................... 6

Chapter 2: Environmental Setting ........................................ 9

Location and Geology .............................................. 9

Climate............................................................. 16

Vegetation......................................................... 18

Earth Science Literature Review.................................. 20

Chapter 3: Cultural Setting............................................... 26

Nevis's Cultural History ........................................... 26

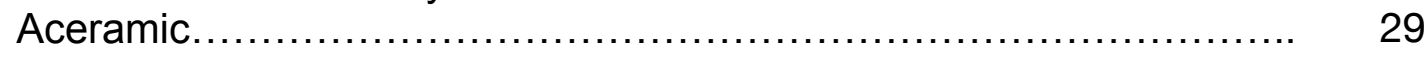

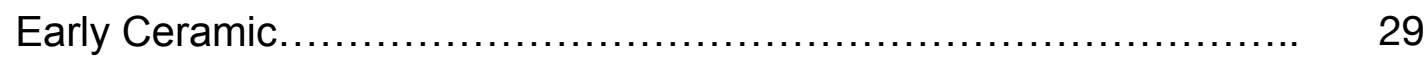

Late Ceramic........................................................ 32

European Contact................................................... 33

Caribbean Culture Literature Review................................ $\quad 35$

Chapter 4: Methodology ................................................. 43

Introduction ......................................................... 43

Recovery Methods ............................................... 50

Laboratory Procedures.............................................. 56

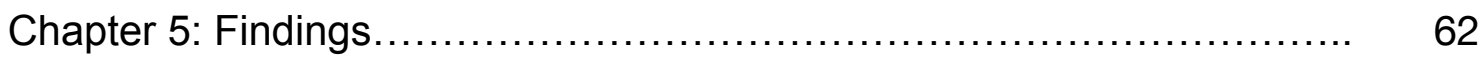

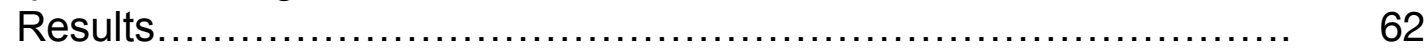

Interpretation...................................................... 71

Discussion......................................................... 74

Chapter 6: Conclusions............................................... 80

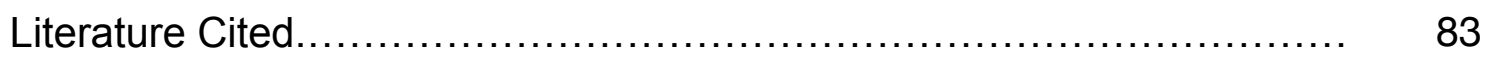




\section{LIST OF TABLES}

Table 1. Clay and Silt Percentages of Total Sample..................... 67 


\section{LIST OF FIGURES}

Figure 1. Map of Caribbean.......................................... 3

Figure 2. Geologic provinces map of the Caribbean Islands............. 10

Figure 3. Geologic provinces map of the Lesser Antilles................ 11

Figure 4. Nevis's location amidst the Lesser Antilles.................... 12

Figure 5. Geographic reference of Nevis............................. 13

Figure 6. Scatters of Volcanic Material............................... 15

Figure 7. Aerial of Windward Coast................................... 20

Figure 8. Sketch of Shell Midden Site ............................... 51

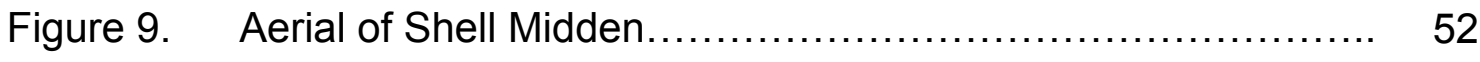

Figure 10. Shell Midden Site........................................ 53

Figure 11. Trench 1 Post-excavation..................................... 53

Figure 12. Trench 2 Pre-excavation.................................. 54

Figure 13. Trench 2 Post-excavation.................................. 55

Figure 14. Trench 2 Post-excavation.................................. 55

Figure 15. Sediment From H1 Under Microscope........................ 57

Figure 16. Clay Distribution Pipette Method............................ 58

Figure 17. SediGraph Machine................................... 59

Figure 18. Dry Sieving Techniques................................... 60

Figure 19. Drawings of Trench 2 Post-excavation........................ 63

Figure 20. Trench 2 North Wall Post-excavation.......................... 64 
Figure 21. Decomposing Shell...................................... 65

Figure 22. Horizon 1 Gravel, Sand, Silt, and Clay ....................... 68

Figure 23. Horizon 2 Gravel, Sand, Silt, and Clay...................... 68

Figure 24. Horizon 3 Gravel, Sand, Silt, and Clay ....................... 69

Figure 25. Horizon 4 Gravel, Sand, Silt, and Clay........................ 69

Figure 26. Cumulative Curves of Coarse-grained Material................ 70

Figure 27. Line Graph of Coarse Grain Material........................ 70

Figure 28. Aerial Photo of Midden Site Drainage Mouth.................. 75 


\section{CHAPTER 1: INTRODUCTION}

Seven thousand years ago, people from North and South America began settling the string of islands that make up the Caribbean (Keegan 2000; Rouse 1951; Wilson 2006). These pre-Colonial people were seafaring traders who traded over long distances from the southern tip of Florida to the northernmost section of Venezuela. Toward the end of the Early Ceramic period (around 500 $\mathrm{CE}$ ), settlement sites dramatically increased throughout the islands, and chiefdoms developed with the expansion of trade routes (Keegan 2000). Just as indigenous societies began to expand and flourish in the Caribbean islands, around $1000 \mathrm{CE}$, archaeologists begin to see a dramatic decline in sites leading up to European settlement in the fifteenth century.

Archaeology in the Caribbean is a growing area of research. The last few decades of fieldwork have revealed a series of Aceramic and Ceramic Age (circa 500 BCE - 1400 CE) sites along the coastline of Nevis (Keegan 2000; Morris et al. 2000; Rouse 1951; Wilson 2006). If these sites are not examined soon, potential data will be lost due to the active coastal erosion and rapid sea level rise. There are still many questions regarding settlement in pre-colonial Nevis, where this research is focused, that have not been answered. Archaeologists are investigating how Nevis's environment influenced indigenous Caribbean culture. If we are truly to understand the prehistory of the Caribbean, it is crucial to explore and expand the knowledge of the prehistoric Carib peoples, including their relationship with Nevis's environment. 
In the summer of 2016, Marco Meniketti of the Department of Anthropology at San Jose State University (SJSU) led a field school on Nevis that explored a Ceramic Age site in the southeastern part of the island. This site on Nevis's eastern coast was originally documented by Wilson (1989). Since then, other projects, including those from Southampton University (Morris et al. 2000, 2001, 2002), William Keegan's research (1994 and 2000), thesis research conducted by Chris Keith of San Jose State University (2014), and Meniketti (2006), have continued to expand the knowledge of the Caribbean. Fieldwork and analysis from my research has bridged aspects of science and humanities through geoarchaeological methods.

The objective of this thesis project is to better understand the prehistoric environment of Nevis by integrating archaeological and geological methodologies. In the contemporary field of archaeology, the methods and results are becoming more precise. Historically, archaeologists have used basic theories of earth science, but in recent decades, researchers have found advanced geological methods more applicable in ways not previously utilized (Merrill 1958; Morris et al. 2000; Wilson 2006). For example, archaeologists can employ grain size analysis to better understand site formation. Other examples include identifying larger minerals under microscopes, associating the sources of grain origin, and assessing the mechanism for sediment transport.

This thesis applies sediment analysis to determine if there was a dramatic transition in the stratigraphy that could indicate types of environmental change. 
The question that drives my research includes: if there was an environmental change, did this change influence the settlement patterns of peoples on Nevis? Although the Colonial Era of Nevis has been thoroughly studied, archaeologists are still exploring the history of human life before European contact (Keegan 1994; Keith 2014; Merrill 1958; Rouse 1951; Wilson 1989).

Nevis, West Indies

Nevis, a small island of about 93.2 square $\mathrm{km}$, located in the Lesser Antilles (Figure 1), has seen dramatic changes over the last 1500 years, both environmentally and culturally.

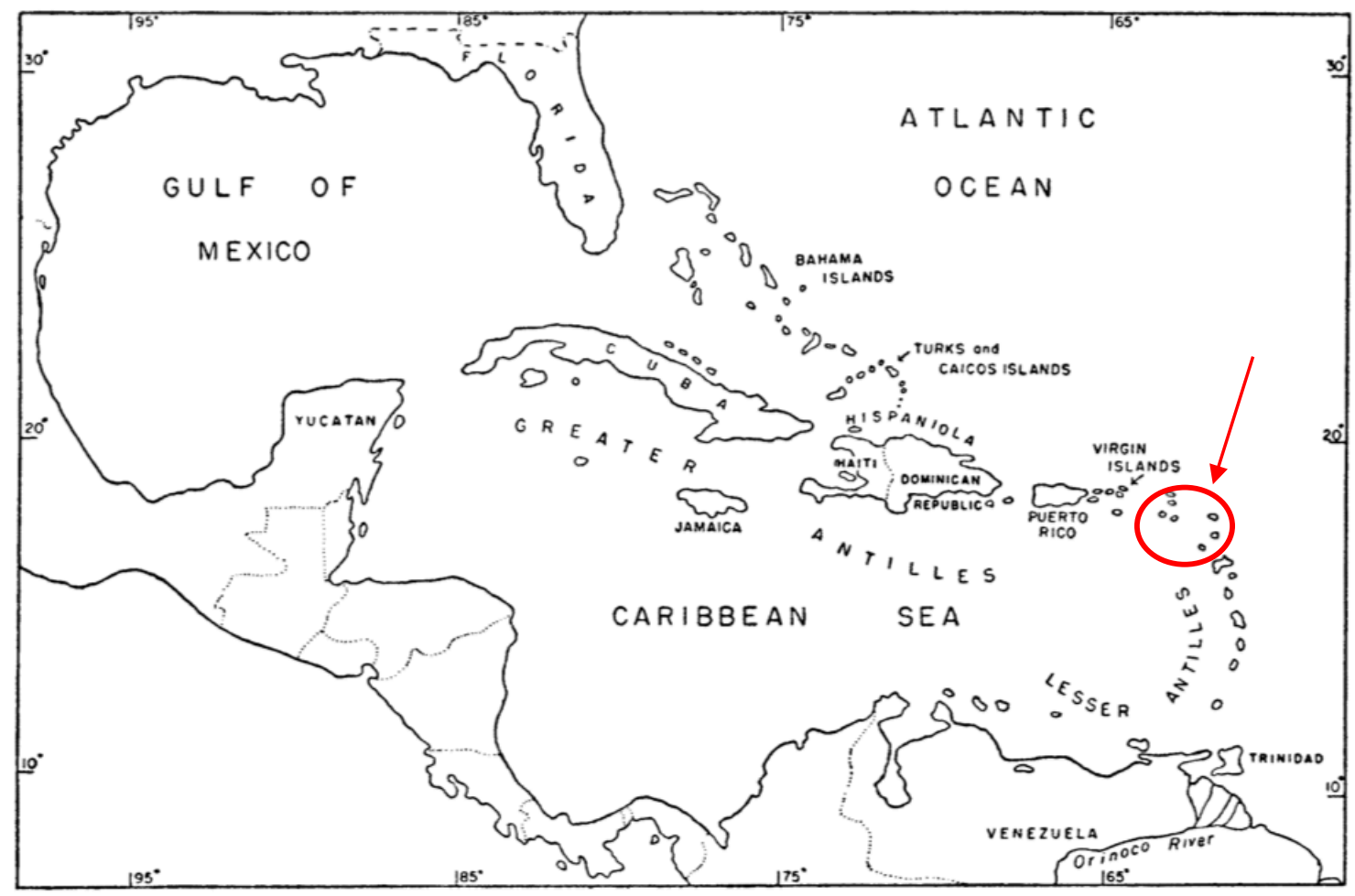

Figure 1. Map of the Caribbean Islands in reference to Central and South America (adapted from Davis and Goodwin 1990). Nevis is circled to show location reference to the Lesser and Greater Antilles. 
The impact of the Colonial Era from the sixteenth to nineteenth century makes the interpretation of Caribbean islands difficult to illustrate due to the environmental site damage (Meniketti 2006, 2015; Wilson 2006). Some of the relevant site impacts include a historic road that was built directly over a shell midden being studied and erosional factors from the nearby ghauts (naturally occurring drainage ditches) flooding from heavy rains. In order to piece together the prehistoric landscape, archaeologists must understand the changes to the historical landscape in addition to the natural alterations caused by climate change.

As a result of its geographical location, there are two different types of coastlines on Nevis. The first is the western Caribbean shore, which has long sandy beaches with no surf. The second is an active shoreline on the eastern, Atlantic side of Nevis. Due to the natural coastal activity, combined with the global change in sea level, these coastlines have influenced the cultural landscape of Nevis since the Early Ceramic era. Field observations and climate data have indicated that Nevis's shoreline has retreated $200 \mathrm{~m}$ inland since the Early Ceramic (Williams 2009; Meniketti, personal communication), meaning that any settlement that may have once sat on the water's edge during the preColonial era is currently covered by water. In the last 30 years, this site has been experiencing dramatic geomorphological changes. For example, a British Geological Society datum point set in 1984 has been nearly consumed by Atlantic wave action (Meniketti, personal communication). 
San Jose State University Nevis Field School 2016

The Nevis Field School of 2016 initiated a multi-faceted interdisciplinary project and contributed to expanding our understanding of pre-Colonial Caribbean history. The objective of my thesis project is expanding the knowledge of Nevis's pre-Colonial past. The primary objectives of this research are to investigate soil composition, survey landscapes surrounding the midden site, and provide necessary evidence to interpret a relationship between cultures of preindustrial Nevis and their environments. The SJSU site contains a prehistoric shell midden documented by Samuel Wilson (1989) that lies 200-500 m south of a village site previously excavated by Southampton University (Morris et al. 2000-2002), and a burial recovered by Chris Keith (2014). This shell midden was a dumping ground for residents of the village, similar to contemporary waste landfills, where people discarded food, clothes, tool remnants, or burials, etc.

In past research, archaeologists (Keegan 2000; Rouse 1964; Wilson 1989, 2006) have discussed a significant change in social patterns during the Ceramic period. As part of the archaeological literature review, I discuss and define this social change as a drastic alteration in social behavior, but the primary focus in this thesis is whether settlement patterns on Nevis were influenced from environmental changes. That is, by examining sediment analysis, can archaeologists use the theoretical concepts and methods of environmental reconstruction to detect site formation processes of the shell midden site? The Carib settlement pattern prior to European settlement (1600s CE) is still unclear 
in the archaeological record on Nevis (Merrill 1958; Rouse 1964; Wilson 2006). However, it is clear is that the first wave (1490s) of European colonization involved slave raiding and disease transmission, initiating a trend that began to weaken the Carib population (Keegan 2017; Merrill 1958; Rouse 1964; Wilson 2006).

\section{Research Questions}

When Columbus sailed by Nevis, there was no indication of people living on the island (Merrill 1958; Wilson 2006). However, there is an early written testimony that Nevis was sparsely inhabited for a short period of time between Columbus's pass by in 1493, and permanent settlement in the 1620s (Wilson 2006). Why was Nevis unoccupied at the time of European colonization? In almost all the literature regarding Nevis, archaeologists and researchers have illustrated a significant cultural change on Nevis and surrounding islands during the late Ceramic Period (Keegan 2000; Morris et al. 2000, 2001, 2002; Wilson 2006). Was this uninhabited state the result of environmental influences? Can we identify these changes through sediment and soil analysis? This thesis intends to provide evidence either to eliminate possible explanations, or to confirm that inconsistent settlement patterns were a result of environmental changes on Nevis.

Nevis Research and Organization of This Thesis

The analysis of Caribbean history, with the evaluation of environmental samples, has contributed to the investigation of Nevis's environment and its 
inhabitants. In Chapter 2 "Environmental Setting," I illustrate what researchers know of Nevis's pre-Colonial history and discuss how landscape reconstruction techniques of past project's have set the foundation for this research. This chapter also incorporates geological literature that provides context for soil and site-forming factors.

Then in Chapter 3, "Cultural Background," I introduce Nevis's cultural history by examining the pre-Colonial timeline of the Carib peoples. While this thesis is primarily an analysis of sediment and stratigraphy, understanding the history of the Carib people is still the overall objective. There have only been a few archaeologists who have lead research specifically on Nevis's prehistory, and while each researcher's methods are similar (Keith 2014; Morris et al. 2000, 2001, 2002; Wilson 2006), there is still debate about certain details that are analyzed later.

Sediment samples were collected during the summer 2016 SJSU Field School, and analyzed throughout the fall of 2016. Chapter 4, "Methodology" of this thesis, I review frameworks and discuss applied methods that were conducted in the field and laboratory. These methods include how samples were randomly collected from a trench dug in the center of the shell midden. Since I had not been to the shell midden site prior to SJSU's fieldwork, there were many uncertainties regarding expectations of the excavation, and in order to move forward, many decisions regarding methods were made on site.

I interpret the sediment samples and stratigraphy from the test pit in chapter 
5 , which includes the results of the data from laboratory methods, a discussion of how I illustrate the data, and an interpretation of how these results connect to the research questions. Then I present the conclusions in chapter 6 that describes how the results and discussion of this project help illustrate the history of Nevis, including an overview of the limitations for this project. 


\section{CHAPTER 2: ENVIRONMENTAL SETTING}

Human histories have always been entangled with landscapes (Crumley and Hornborg 2007). In order to fully understand the pasts of pre-Colonial people in the Caribbean, we must first have a comprehensive knowledge of the geologic activity and environmental changes that have occurred over time. Nevis's dynamic landscape is influenced by many contributing factors, including volcanic activity, climate, vegetation, decomposition and erosion, and human activity. In this chapter, I introduce the geologic background of the Caribbean and describe Nevis's environmental setting. Next, I go into detail regarding the climatic influences that have shaped the evolution of vegetation on the island. Landscape forming processes are explained by geologic theories. For example, earthquakes are explained by the theory of plate tectonics. The second part of this chapter is a literature review of different scientific methods used by individual researchers. These research projects have included different analyses of Nevis's environment and landscape, which have influenced my thesis research.

\section{Location and Geology}

The Caribbean is a large, tectonically active region near the equator that includes the Caribbean Sea and various chains of islands (Figure 2). Some of these islands are made of sedimentary rocks and are relatively flat, whereas others are mountainous and volcanic. The islands that are of volcanic origin represent tectonic boundaries between the three main plates: the Caribbean plate, the South American plate, and the North American plate. While plate 
boundaries are more geologically complicated, for the sake of this research, we are only examining the general subduction boundary between the South American and the Caribbean plates.

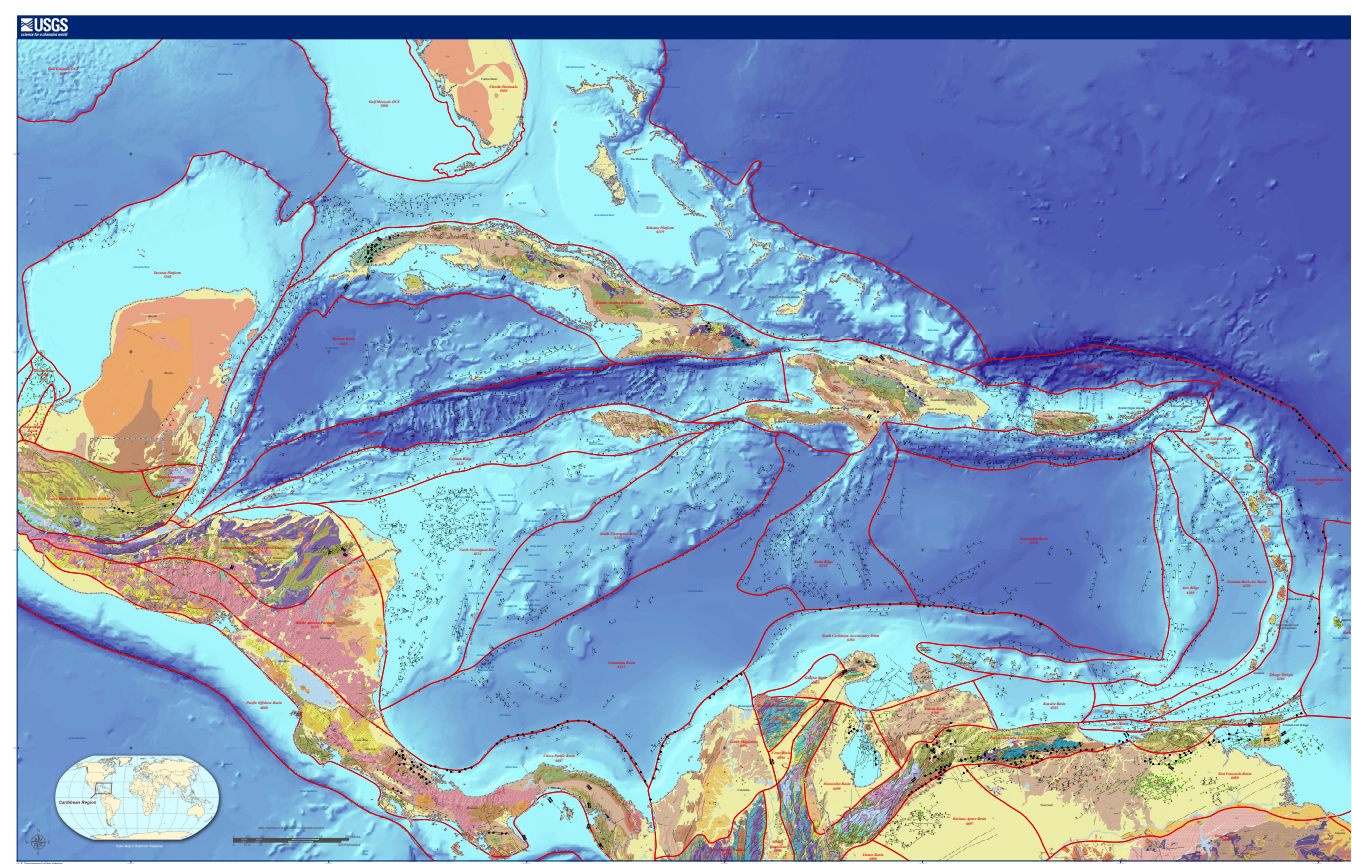

Figure 2. Geologic provinces map of the Caribbean Islands. Central America pictured left, and South America pictured bottom right (U.S. Geological Survey 2017).

The Lesser Antilles subduction zone is just southeast of the three largest Caribbean islands: Cuba, Haiti/Dominican Republic, and Puerto Rico (Figure 3). This zone occurs where the cooler and denser plate (South American plate) subducts under the Caribbean plate (The Geological Society of London 2017). The subduction occurrence results in frequent earthquakes in a region known as a Benioff zone (The Geological Society of London 2017). As the subduction of the South American plate continues, it carries seawater trapped in the crust down into the mantle. This process causes the plate to heat the seawater, and then 
release it, resulting in partial melting of the mantle (The Geological Society of London 2017). Magma produced at the melting point then rises to the surface, causing an eruption of andesite at the earth's surface (The Geological Society of London 2017). There are seventeen active volcanoes of calc-alkaline composition illustrating this process on the eastern boundary of the Caribbean plate (Bouysse 1990).

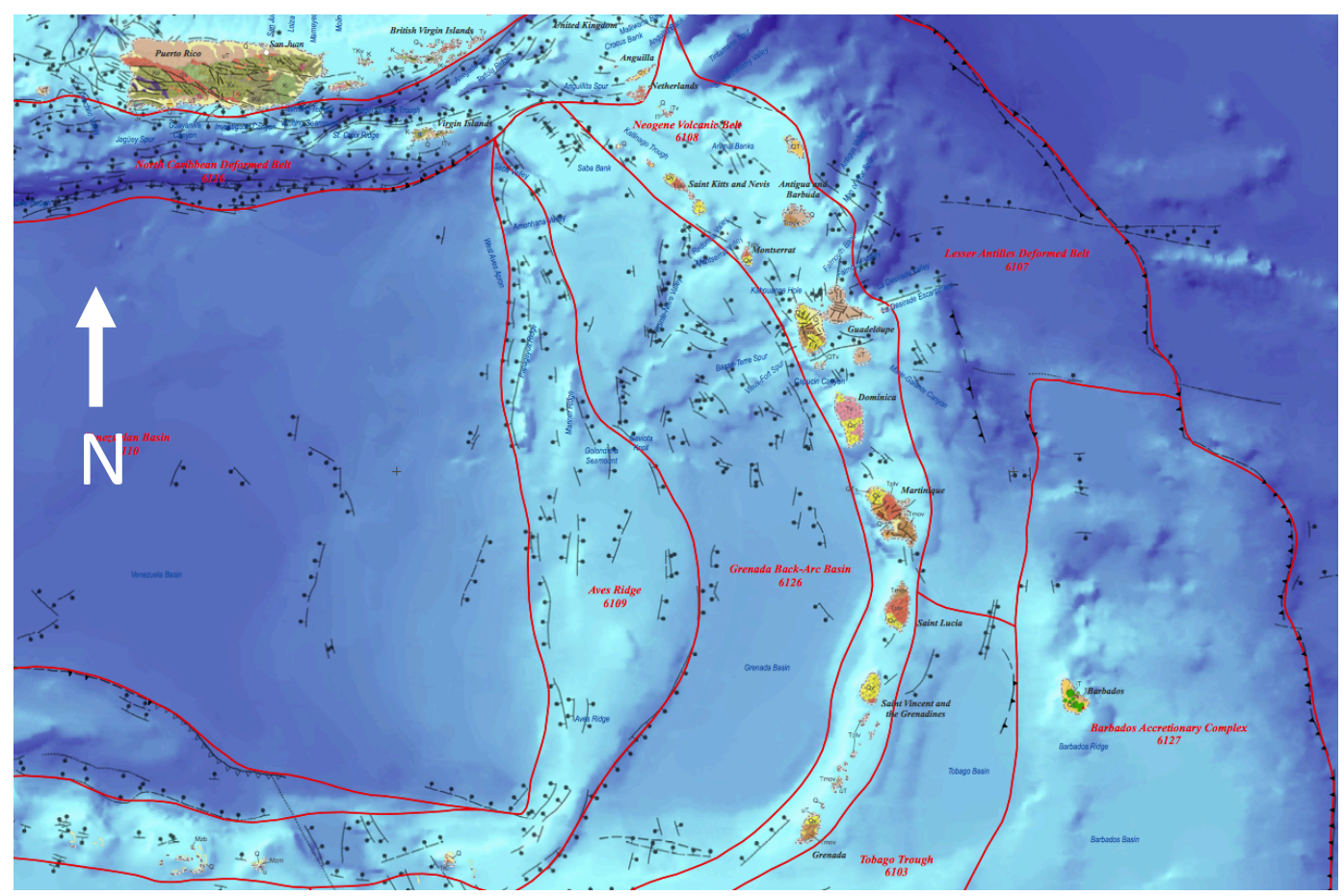

Figure 3. A geological provinces map of the Lesser Antilles, the larger island in the upper left corner is Puerto Rico (U.S. Geological Survey 2017).

Located in the northern region of the Leeward Islands is the small circular island of Nevis (Figure 4). Its total area reaching 93 square $\mathrm{km}$ and its highest peak reaching $985 \mathrm{~m}$, Nevis sits adjacent to the island of St. Kitts and $48 \mathrm{~km}$ northwest of Montserrat (Figure 5) (The University of the West Indies Seismic Research Centre 2017). Although Nevis is a small island, it contains multiple landscapes and active coastlines. The Atlantic portion, or the "windward" side of 
Nevis peak encounters trade winds from the east, whereas the Caribbean side of the island features calm and sandy beaches.

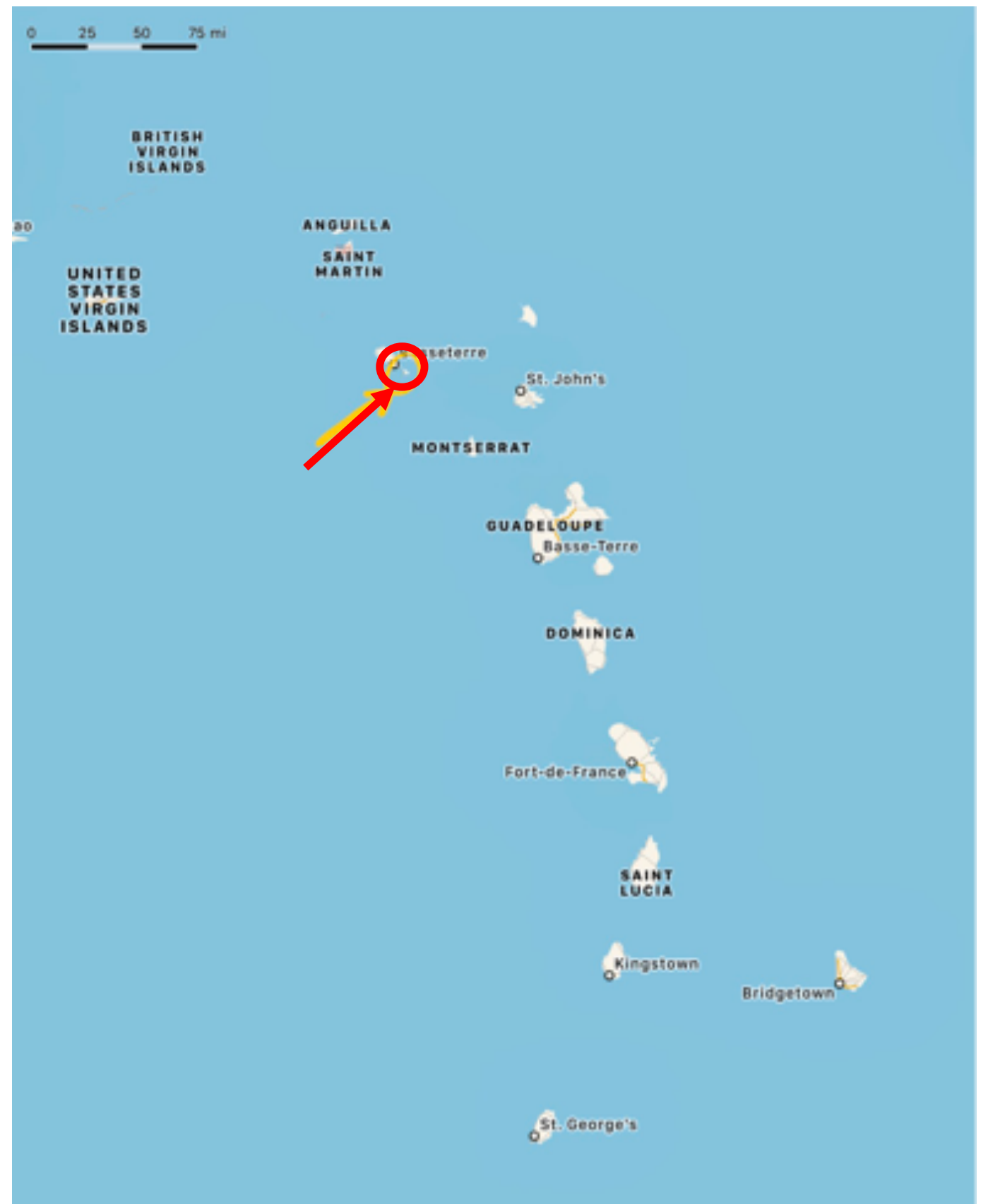

Figure 4. Nevis's location (arrow) amidst the Lesser Antilles Volcanic chain, top of the page is North (Google Maps). 


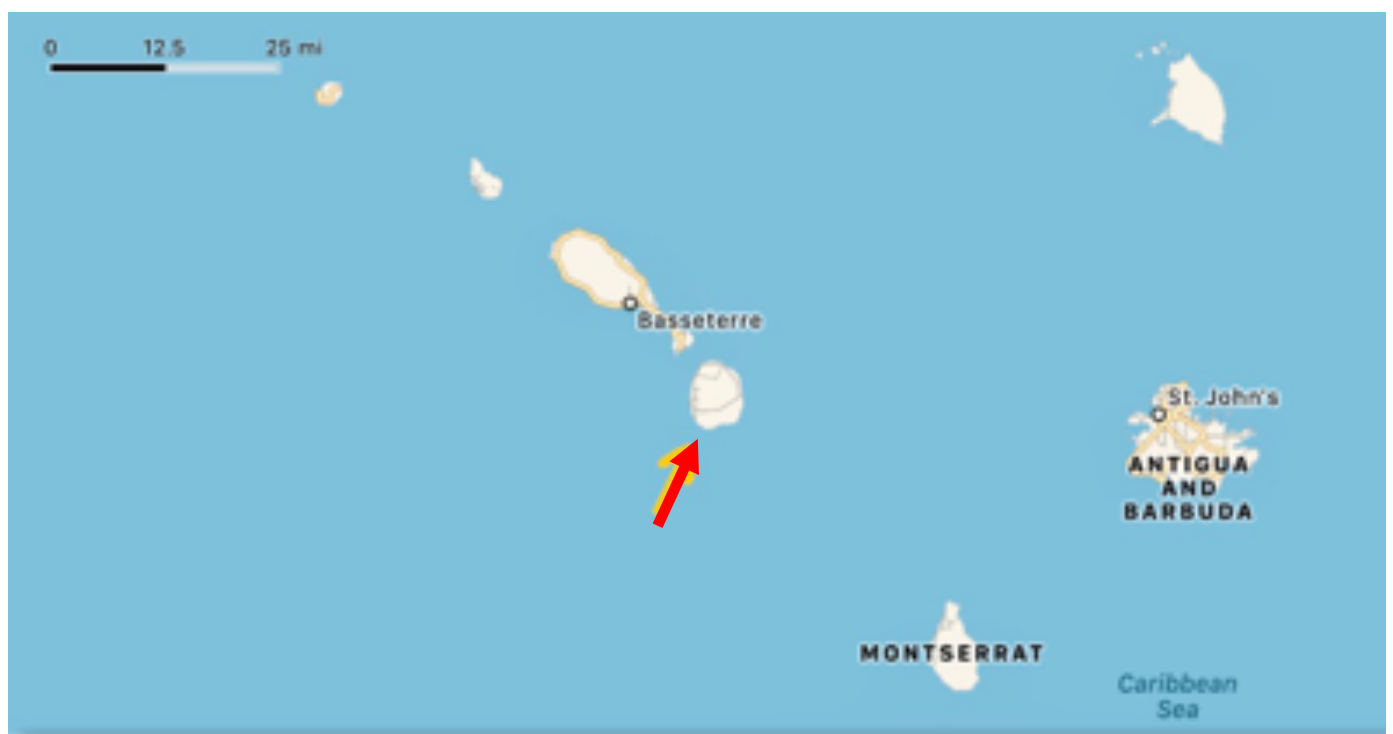

Figure 5. Geographic location of Nevis, centered round island (arrow), relative to St. Kitts (northwest), Montserrat (southeast), and Antigua (east) (Google maps).

The landscape of Nevis is cone-shaped with a volcanic peak. The island itself is primarily composed of volcanic material including volcanic eruptive centers, pyroclastic flows, lahars, and raised beaches (The University of the West Indies Seismic Research Centre 2017). According to the historical record, there is no evidence of Nevis erupting in the presence of humans, and the youngest volcanic rock found is about 0.1 million years old (Koon Koon 2012). However, there have been multiple earthquakes recorded post European settlement. Nevis is currently experiencing hydrothermal activity, which is demonstrated by the multiple hot springs scattered over the island. It has been speculated, however, that Nevis has experienced more recent volcanic activity from lava domes collapsing and generating pyroclastic flows, which contribute to the gentle slope topography we see today (Merrill 1958; The University of the West Indies Seismic Research Centre 2017). The only evidence that has been produced supporting this 
hypothesis is a single individual's observation. Nevis's volcanic material is primarily composed of andesite and dacite (The University of the West Indies Seismic Research Centre 2017). The mineral composition of andesite includes pyroxene (augite), plagioclase, and amphibole (hornblende). Dacite is similar, but it also includes biotite and quartz. These two extrusive rocks are usually associated together forming lava flows (The Geological Society of London 2017).

On the nearby island of Montserrat rests an active volcano only $48.3 \mathrm{~km}$ from the southeastern coast of Nevis. Although this volcano is some distance away, with the right winds, it could potentially be very dangerous to Nevis. The eruption that occurred on Montserrat in 1997 covered Nevis in about 2-3 mm of ash on the south coast (Meniketti, Personal Communication). These two volcanoes are part of the same island chain and produce very similar geologic material. Although Nevis shows no signs of recent eruption, it is covered with volcanic rock and tuff. Without a more detailed study of these materials, it is nearly impossible to distinguish Nevis's volcanic material from Montserrat's, except for the pumice lapilli fall deposit from Montserrat (The University of the West Indies Seismic Research Centre 2017).

Nevis's windward beaches are scattered with exposed volcanic material (Figure 6). While walking around SJSU's field site last summer, one could find baseball-sized pieces of Montserrat pumice from one of its historic eruptions. The pumice material demonstrates that $48.3 \mathrm{~km}$ of water does not protect the cultural sites on Nevis's windward coast. Under the right conditions, an eruption could 
greatly affect human activity on Nevis. Although the geologic history of Montserrat before the colonization of the island is still unknown, field excavations on Nevis have not reported significant amounts of ash that could be related to a pre-colonial cultural change. However, weathering factors could contribute to the absence of recent volcanic activity. In this thesis, I acknowledge the need for further volcanic study and analysis, but it is beyond the scope of this research.

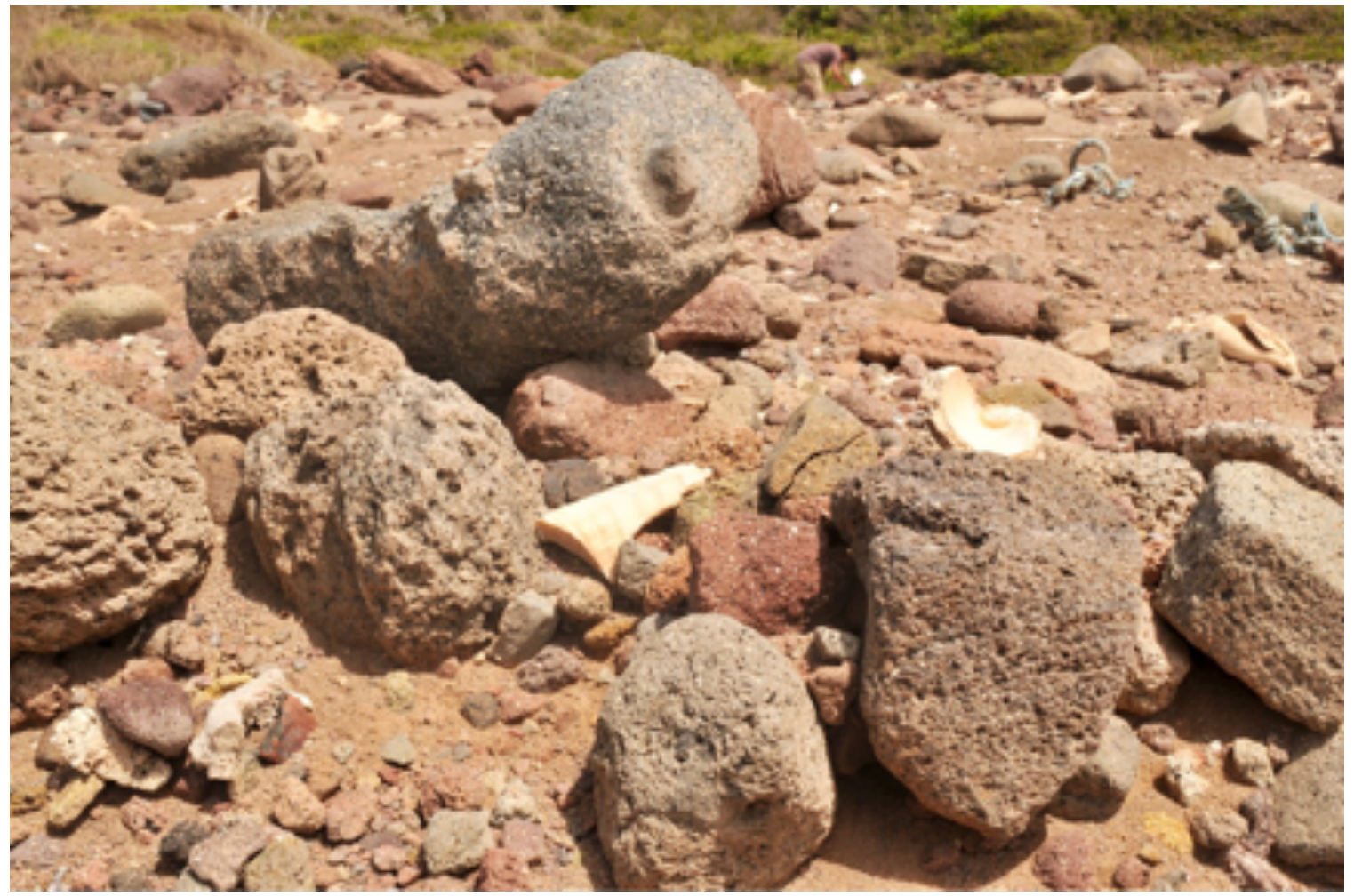

Figure 6: Scatters of volcanic material; rocks pictured are larger than a softball, but smaller than a basketball.

Aside from the volcanic activity, other environmental factors put Nevis's landscape at risk. Natural environmental risks include dramatic coastline changes and heavy rainfall. This region is an active coastal area that is slowly disappearing. The heavy rainfall from massive hurricanes is morphing and 
transforming the island landscape every year. Meniketti $(2006,2015)$ illustrated how the vegetation has changed dramatically on the island of Nevis since the beginning of the industrial period. Nevis was once a rainforest island with green tropical plants; however, the current state of the eastern portion of the island shows that it has changed (Wilson 2006). When European colonists stripped the island of its original vegetation and replaced it with sugarcane, hurricane storms washed away much, if not all, of the original topsoil (Meniketti 2006, 2015; Wilson 2006). The harder sediment originally beneath the fertile soil was then exposed.

The harder soil could not soak up the rainwater, resulting in runoff that left the land barren (Wilson 2006). Meniketti (2015) and Wilson (2006) illustrated how these conditions could partially explain why Carib peoples originally settled on the eastern coast of what is now "barren landscape," as it was once a lush tropical forests. Goldberg et al. (2001) focused on how earth science relates to archaeology. One chapter of Goldberg's specifically connects the two fields by explaining how the Quaternary physical science can be related to the more recent archaeological social science. A chapter entitled "A Review of Site Formation Processes and Their Relevance to Geoarchaeology," discusses how soil formation processes relate to archaeology, and how patterns in stratigraphy can inform the archaeologist of cultural components.

\section{Climate}

Climate is a fundamental component of the physical environment, including soil-forming factors. Through stratigraphic analysis, archaeologists can begin to 
illustrate how the SJSU Field site has been affected by the change in climate. While this research is not about climate change, it is still important to understand the rate at which soils and sediments are constructed and how the landscape has changed. Previous researchers have discussed the possibility of the Caribbean historically experiencing a much drier climate than we see throughout the islands today (Higuera-Gundy et al. 1999; Hodell et al. 1991; Keegan and Hofman 2017; Siegel et al. 2015; Wilson 2006). According to Keegan and Hofman (2017), about 3,200 years ago the climate became much drier than it had been, and it was not until 1,000 years ago that it returned to the humid state we experience today. While most of the geological timeline of Nevis is not directly relevant to the first human settlement on the island, it still remains essential for understanding the distinction between different horizons observed in this study.

The retreating coastlines are also attributed to the prevailing climate, which is not a constant variable. There have been proposals explaining how sea-level has been slowly rising about $1.8 \mathrm{~mm} /$ year from 1961-1993, then $3.1 \mathrm{~mm} /$ year from 1993-2003 (Williams 2009). Although Williams' study only looks at recent decades into the past, it still illustrates how coastlines have changed in just a short period of time. Since the occupation of pre-Colonial peoples on Nevis, there has been considerable changes in coastlines due to erosion of active coastal zones. For example, Nevis's windward coast has been experiencing a combination of slight sea-level rise in very shallow waters, erosion happening from heavy rain runoff, and active tidal zones pounding on beaches and washing 
away island material. Since pre-Colonial Carib peoples were inhabiting the island, the shoreline has retreated about $200 \mathrm{~m}$ inland (Ruppe 1979).

Coastal archaeological sites are most affected by this change because, as a coastline recedes, sites that previously had a waterfront view have eroded away, and it is much more difficult to examine these sites (Kraft et al. 1975). Unfortunately, active tidal zones do not preserve archaeological materials, and these materials are usually swept away and dispersed. Redcliff is a geologic landmark on the southeastern coastline of Nevis that was once a large volcanic cone, but now only remnants remain from the eroding wave action (The University of the West Indies Seismic Research Centre 2017). Other historical landmarks, including canons, defense walls, and a Colonial cemetery that were once exposed on the opposite side of the island, are now covered by water and sand on Nevis's western coast. In the field, the repercussions of large hurricanes have been observed throughout the West Indies. Past storms have ripped out the beaches on Nevis's western coastline, exposing the historical sites, which then have become covered again with the changing tides.

\section{Vegetation}

The vegetation on pre-Colonial Nevis was different from what is seen today, and this fact contributes to theories of climate change and settlement. The current vegetation on Nevis shows that the windward side of the island is more barren than the western region due to land modification during the historical period. Walking around the SJSU field site, it was quite noticeable that there are 
large areas of extremely dry, cracking clay surface, and other portions of possibly windblown and alluvial sand. Previously, much of this area was used for cultivating sugar cane. However, this area cannot be used for agriculture because the tillable topsoil has been washed away over the years, so the islanders built a horse race track near the southeast part of the island (Meniketti, Personal Communication).

As mentioned before, during the pre-Colonial era of Nevis, its windward side was covered by lush tropical climax rainforest (Wilson 2006). The landscape change was initiated upon European arrival, and the repercussions that followed were due to environmentally destructive actions of Colonial settlers. For archaeologists, it is essential to recognize how much the landscape has changed since the time of its settlement period and leading up to the project excavation.

The rainfall on Nevis ranges from $740 \mathrm{~mm}$ to $1295.4 \mathrm{~mm}$ a year (Wilson 2006), and before Colonial deforestation, the forest soils and roots would soak up the rainwater. However, since Europeans clear-cut the land for plantation use, the heavy rains have resulted in rapid runoff. Meniketti (2015) suggests that this clear-cutting had reached altitudes up to $2000 \mathrm{ft}$ on Nevis. This process has consistently been altering the landscape. During cultivation periods, plantation owners were forced to import soil for agriculture due to the constant runoff (Meniketti 2015). During the rainy season on Nevis, it has been observed that ghauts (large temporary drainage ditches carved into the landscape by erosion) fill up quickly for short periods of time with material including cars, people, and 
trees (Wilson 2006). Aerial photography illustrates the deep ghauts carved out of the surface over the many years of drainage and heavy rainfall (Figure 7).

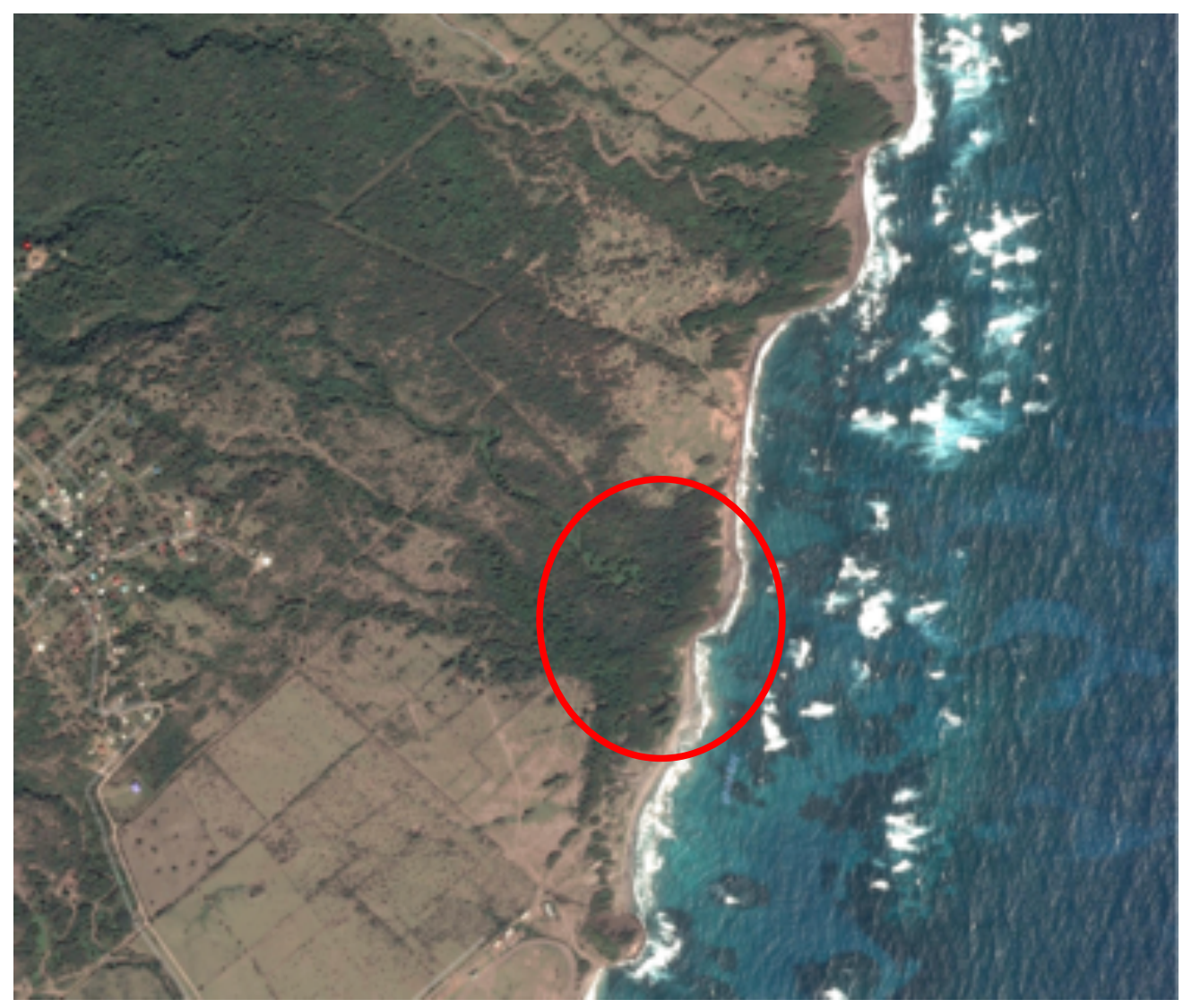

Figure 7. Aerial photograph of site region and landscape; drainage patterns marked by vegetation. Top of the photo is north, the ocean is east, and there is a town pictured on the middle left. Notice also, plantations expressed in grid like patterns (Google Earth 2017).

Earth Science Literature Review.

The "Historical Geography of St. Kitts and Nevis, The West Indies," by Merrill (1958), gives a geological history of how Nevis and its peak appeared in the 1950s. Merrill's work may be considered dated by most researchers; however, it gives contemporary archaeologists a window into the past of how this geography appeared 60 years ago. As discussed previously, Nevis is a dynamic 
environment that is constantly changing due to climate, sea level change, and erosion. Therefore, literature such as this is crucial because a feature observed 60 years ago may not be present today. Previously, I mentioned that it has been thought that Nevis experienced some recent activity, including a partial collapse of the dome. While there is no evidence of Nevis peak erupting within recent human history on the island, there are early writings describing visual evidence of a recent collapse of the dome not long before the colonists' arrival (Merrill 1958).

In addition to the geographical overview, Merrill also discusses journal writings from the time of Columbus's arrival on St. Kitts. According to Merrill's research, St. Kitts was easily conquered by the massacre of the indigenous people (Merrill 1958). Merrill also illustrates that, when Nevis was first settled by Europeans, they claimed that the island was not inhabited by any people (Merrill 1958). The surrounding islands, including St. Kitts and Montserrat, were settled by Kalinago Caribs, but Nevis was uninhabited. However, early colonists constructed a plantation on a mound recognized as a carib village site so abandonment might have been recent.

One concern with Merrill's research is that he gives valuable information, but does not describe his methods. Merrill's (1958) book, is rich with information and provides photos of historical sites on St. Kitts in the later chapters, but Merrill does not include how he obtained his results. This work reads more like a literature review, rather than an archaeological report. One of my secondary goals in this thesis is to give detailed descriptions of how my results were 
acquired, so future researchers can build upon this foundation.

The geologic complexity of Nevis and the Lesser Antilles is crucial to understanding the evolution of their landscape in this environmental reconstruction. Most archaeological research projects on Nevis in the past have included a brief geological or environmental report. Some, including Samuel M. Wilson's (1981, 1985, 2006), and Southampton's (Morris et al. 2000, 2001, 2002) are more in depth than others. Wilson's book gives a thorough geologic, climatic, and overview of the Caribs societies on Nevis. Wilson discussed the prehistoric sites on Nevis that had been excavated leading up to 2006. This source is crucial to this research because it is specifically related to the SJSU Field School of 2016 and my research questions.

Wilson (2006) conducted three years of fieldwork, which encompassed surveying everything below $300 \mathrm{~m}$ of elevation along the entire coastline of Nevis. Wilson's field crew also checked streamlines for any evidence of settlement up to $500 \mathrm{~m}$ above sea level. There were only four sites excavated out of the many pre-Colonial sites recorded by Wilson's crew. Over the three seasons of fieldwork, sediment samples of two liters were collected from each of ten $1 \times 1-m$ test pits. Other test pits ranged from $2 \times 2-m$ to $1 \times 3-m$, and sixteen column samples were collected from these trenches. Wilson discusses how the samples come from shallow, unstratified, homogeneous units. This informs readers that their sampling was not representative of the true soil distribution.

Wilson's analysis was represented by a large sample size, however, his 
methods mostly focused on wood taxonomies and seed speciation rather than specific sediment analysis. Paleoethnobotanical investigations are important for reconstructing landscapes and how people interacted with their environments, but they do not inform archaeologists of site formation.

Water floatation was the primary laboratory method used in separating materials. This is a process where samples are dumped into large buckets of water; anything that floats could be interpreted as anthropogenic. The floating materials were skimmed off the surface and further analyzed. Through the flotation test, the two predominant findings were various types of seeds and wood. The seeds Wilson's project found were small and spherical and were apparently used for medicinal purposes. During the 2016 SJSU field school we also came across similar seeds. Although, there was no evidence the seeds we found were anthropogenic.

Whereas most of Southampton University Nevis Heritage Project's research focused on ceramic analysis, the project also examined a small geological aspect of the region through test pits, stratigraphic sketches, and a brief soil analysis. Similar to Wilson's work, Southampton excavated and analyzed nineteen test pits over three consecutive summers of fieldwork. The project's goal was to provide a base geological and consecutive depositional sequence of soils across the site (Morris et al. 2002). Southampton's primary laboratory methods included floatation tests, much like Wilson.

Through soil mapping in 2002, the Nevis Heritage Project reported that a 
majority of the island soils were formed on volcanic deposits $(75 \%)$, ghaut deposits $(10 \%)$, and beach sand deposits $(2 \%)$, leaving inaccessible soils unmapped (13\%) (Morris et al. 2002). Although the timing and causes of the loss of topsoil are not discussed, Southampton reported that Hichman's site had lost over fifty percent of its original topsoil. However, the Historic Era sugar plantations were a likely factor for this loss. At the end of the project report, Southampton argued there is great potential for future survey and excavation to further analyze and explore the southern half of these sites, which is where SJSU picked up.

Environmental reconstructions are not usually completed in one project; rather they are conducted over long periods of time by multiple projects. Furthermore, the evidence from this thesis research builds on the environmental foundation from Merrill's (1958) observations, Wilson's conclusions, and the Nevis Heritage Project by Southampton University (Morris et al. 2002), by delving more into a laboratory sediment analysis. Wilson's and Southampton's projects took large soil samples, but no specific sediment analysis is performed with regard to site formation. Rather, their reports are very detailed in how specific organic materials describe land use of the inhabitants. This thesis uses more geologic evidence to explore site formation processes and the possibility of an abrupt environmental change during the Ceramic Era.

Over time, Nevis has experienced many interactions with diverse groups of human inhabiters. In the following chapter 3 , I discuss the cultural background of 
Nevis, beginning with the first settlers, leading up to European contact. Each group that was once living on Nevis, has left a different impact which can be seen in the archaeological record. These environmental repercussions can give archaeologists insight into what relationships different people had with the landscape at various time. 


\section{CHAPTER 3: CULTURAL SETTING}

The Caribbean's cultural history entails multiple waves of different people migrating to various islands from difference source populations. The history of these pre-Colonial people is rather unclear, and researchers and archaeologists are still trying to clarify certain prehistoric sequences. The first half of this chapter is a sequential synopsis of what is known of today with regard to Carib people's history leading up to Colonial contact. However, because this history is still uncertain, the second half of this chapter discusses the conflicting theories of how eras are organized and the possibility that these people were absent during Colonial settlement.

Nevis's Cultural History

Keegan (1994) discussed the development of archaeological recovery in the Lesser Antilles. These archaeological projects continue as researchers delve into deeper questions about the Caribbean prehistory (Keegan 1994; Wilson 1989). As archaeologists continue to unravel pre-Colonial life, they have begun to realize how connected these islands were culturally due to their geographic proximity. While people throughout the Caribbean have associated themselves with different social groups, the geographic construction of island chains forced people to go beyond the island confinements, and either trade or find resources elsewhere (Sleight 1965; Wilson 2006). As a result of needing to explore what was outside of their island, these people developed efficient canoe travel, which continued to push the island frontier (Nicholson 1975; Rouse 1969). Evidence of 
these trade routes is scattered throughout the Antilles, including Antiguan chert tools, patterned ceramics, and various minerals. These findings confirm that these different social groups were intermingling and settling throughout the two different island chains. Due to the geologic make up of each island, the chert debitage found on Nevis can only belong to one island, Antigua (Keegan 2000; Wilson 2006).

Through carbon-14 dating methods, archaeologists have suggested that the larger islands could have been inhabited as early as 5000 BCE (Fitzpatrick 2006; Keegan and Hofman 2017; Wilson 2007). Archaeologists have proved that people living on larger islands (Puerto Rico, Cuba, and Jamaica) took long and multiple leaps of exploration, rather than one constant trail of gradual advancement (Wilson 2007). However, more of the carbon-14 dates illustrate that the indigenous people have been inhabiting the Caribbean since 3330 years ago (Fitzpatrick 2006; Roksandic et al. 2015; Wilson 1989). Although there have been a few earlier dates, we know there were large waves of people migrating and settling the Caribbean islands at least 3000 years ago (Fitzpatrick 2006; Keith 2014; Rouse 1964; Wilson 2006).

Upon Columbus's arrival in the Caribbean, he encountered three scattered societies: the Ciboney, Arawak, and the Carib (Rouse 1951). The least documented are the Ciboney; they are said to have lived on or around the region of Cuba, in caves and or camps, getting their food by hunting, fishing, and gathering (Rouse 1951). In contrast, the horticulturist groups were pottery- 
making Arawak people that occupied the rest of the Greater Antilles (Rouse 1951). The people who pertain to my research are the Caribs, who were centered in the Lesser Antilles (Davis and Goodwin 1990). However, today's surviving descendants of the Caribbean prefer the ethnonym Kalinago. For the purpose of this research, I will address the population on Nevis as Caribs to be consistent with earlier researchers. Rouse $(1951,1964)$ cites Columbus's hypothesis that these warlike peoples were cannibals; however, there is no evidence that supports these claims from recent skeletal analysis, and the people were only viewed as warlike because they resisted enslavement (Keith 2014).

The earliest dates for Carib peoples migrating to Nevis extends back to at least 500 BCE (Keegan 2000). The occupation of pre-Colonial people on Nevis has been organized into three main phases with some subdivisions. These general episodes have been roughly categorized into the Aceramic period (preCeramic) before $500 \mathrm{BCE}$, Early Ceramic period $500 \mathrm{BCE}$ to $500 \mathrm{CE}$, and the Late Ceramic $500 \mathrm{CE}$, leading up to European contact in the sixteenth century (Keith 2014; Merrill 1958; Morris et al. 2000; Wilson 1989, 2006).

There have been differences in opinion about the arrangement of the Early and Late Ceramic phases, and how they are subdivided. Rouse (1961) describes the pre-Ceramic Era followed by three Ceramic sub-periods and characterizes them with Roman numerals. However, Southampton (Morris et al. 2000, 2001, 2002) and Wilson (2006) discuss the Aceramic Era as the earliest phase, whereas Wilson's later works coincide with Keith (2014), illustrating the first 
phase as "Cedrosan-Saladoid." The age ranges of each site differ slightly as well. However, for the purposes of this research, we will acknowledge three main phases of Carib settlement during the prehistoric "pre-industrial" time period of Nevis (the Aceramic, Ceramic, and the Late Ceramic) following Merrill (1958), Morris et al. (2000), and Wilson (2006).

Aceramic

The Aceramic, also known as the pre-Ceramic, is the first period of human settlement on Nevis. The earliest dates for Caribs beginning to settle the island have been speculated to reach as far back as 3,000 years, but for this research we will describe the Aceramic period as any site dated previous to $500 \mathrm{BCE}$. This period of Caribbean history is still being explored. There is not enough evidence at this point to say when exactly the first people came to Nevis, but we know it was well before 500 BCE (Roksandic et al. 2015; Rouse 1964; Wison 2006). There are only two Aceramic sites that archaeologists know of on Nevis, Hichman's Shell Heap and the Nisbett site. Both of these sites have been dated to 500 BCE (Wilson 2006). These are both small sites adjacent to large coral reefs and stream beds that would have been flowing with fresh water at some point (Wilson 1989). Evidence at the Hichman and Nisbett sites includes mostly scatters of shell, bone, and chert tools (Wilson 1989).

\section{Early Ceramic}

The Early Ceramic period "Saladoid" has been further broken into three subperiods: the Cedrosan-Saladoid subseries (500 BCE to OCE), the Huecan- 
Saladoid subseries (0 to $350 \mathrm{CE}$ ), and the Barrancoid-Saladoid subseries (350 to 500 CE) (Keith 2014; Wilson 1997, 2006). The Cedrosan-Saladoid material was found at depths below $20 \mathrm{~cm}$ in most test pits (Wilson 2006). Plain and patterned pottery with specific shapes and rims represent this period. The Huecan-Saladoid subseries is thought by many to represent a different culture, because of the change in pottery patterning, but most people still believe this represents differences within an evolving culture (Keith 2014).

Many authors have debated whether changes in pottery patterns represent different settlements, but Wilson's analysis of Goodwin's work from 1979 illustrates that during the first millennium, Saladoid societies of the Lesser Antilles underwent some changes that archaeologists today still do not fully understand (Keegan 2000; Rouse 1964; Wilson 1989, 2006). The period in which this change becomes the most obvious is the Barrancoid-Saladoid subseries, ranging from 350 to $500 \mathrm{CE}$. During this time, pottery decorations became more complex, and they appear to reflect a more philosophical and spiritual society (Keith 2014; Rouse 1964; Wilson 1989). From the archaeological faunal record, we can see that food preferences changed drastically; this could mean there was an overexploitation of resources or some type of technological innovation, but the evidence is not clear. Other changes followed but at different paces, including housing structure, settlement location, population size, and pattern styles in the ceramics (Goodwin 1979; Wilson 1989).

One of the factors possibly contributing to this "change" during the later years 
of the Early Ceramic period is a population boom. The coastal areas of South America and the Caribbean were experiencing a dramatic rise in population, which can be seen through an increasing number of settlement sites (Keith 2014; Righter 1991). However, it has also has been hypothesized that there was not a population increase, but that these peoples were becoming more mobile (Keith 2014; Righter 1991). Most likely the long distance trade routes support the idea that the same group of people were settling in multiple locations across different island chains (Keith 2014; Righter 1991).

The most common example of evidence illustrating the long-distance trade route is the Antiguan chert. Chert is a rock that was commonly knapped into a variety of different tools. This particular rock is only found on one island, Antigua, yet pieces are scattered throughout the Caribbean islands (Keegan 2000; Keith 2014; Watters and Donahue 1985; Watters 1997). Another example is beads found on Montserrat. Beads that were found in pre-Colonial sites are made from Carnelian, Turquoise, Quartzite, Amethyst, and Nephrite Jade. However, none of these minerals or rocks are from Montserrat. The exact origin of each of these materials is still being studied, but they are most likely from other islands or South America (Watters and Donahue 1985). Lastly, analysis of the pottery from Barbuda reveals that its makeup is a volcanic temper, which does not match the native material on the island. The pottery analysis suggests that it was brought from an outside source, and found its ultimate resting place in Barbuda, which is a carbonate island (Allaire 2008; Watters and Donahue 1985). 


\section{Late Ceramic}

The Late Ceramic, also known as Post-Saladoid or "Ostionoid" technology, leads up to European contact. The timing of contact between Europeans and Caribs is unclear because Europeans initially sailed by Nevis. Columbus's written record describes seeing people canoeing off in the distance, whereas others landed and saw no evidence of inhabitants (Wilson 2006). During this period, the population continued to grow throughout the Caribbean, and this is visible with the increase of sites on Nevis (Keegan 2000; Wilson 1993). Both the Southampton (Morris et al. 2000, 2001, 2002) village site and Chris Keith's (2014) research site coincide with the location of the shell midden from San Jose State University's 2016 Nevis Field School, and they have been dated to the Late Ceramic period. Originally, it was thought that Nevis was abandoned by $500 \mathrm{CE}$, but recent unpublished dating by the SJSU field school has shown that people were living on the island more recently than previously thought (Keith 2014; Wilson 2006). For example, it had been previously thought the island was deserted by $500 \mathrm{CE}$, however, recent dates have shown people living on the island up to $1000-1200$ CE (Personal Communication, Meniketti).

Before European contact and acts of clear cutting, some of the Lesser Antilles volcanic islands contained soil that was ideal for cultivation (Keith 2014). The islands that had no tillable soil were not settled until much later, toward the end of the Ceramic Era (Keith 2014). Leading up to this point, these people were mostly fishers and gatherers, but evidence of horticultural societies during the Late 
Ceramic period has emerged. This was most likely due to the evolving trade routes that allowed people to spread ideas and foods from agricultural societies on the mainlands of Central and South America. The most common crops that have been found through dental isotope analysis are: Maranta arundinacea (arrowroot), Mammea americana (mamey apple), Carica papaya (papaya), Psidium guajava (guava), Ipomoea batatas (sweet potato), and Z. mays subsp. Mays (maize) (Rouse 1964; Wilson 2006). The people extracted resources from the landscapes and introduced new non-native plants to the ecosystem, which changed the quality of life (Keith 2014).

Researchers have recognized how Caribbean people adapted to their environments and went outside their island confinement to seek resources they needed or wanted by open sea travel (Allaire 1997; Keegan 2000; Keith 2014; Nicholson 1975; Wilson 2006). Through the archaeological record, certain materials have been identified, providing evidence of harvesting of a variety of wood for deep sea canoe travel. Other materials provide evidence for fishing, the use of sap from the manchineel tree for dipping longbows, utilizing chili pepper juice for poisonous darts, and incorporating cotton for weaving (Allaire 1997).

\section{European Contact}

The Caribbean experienced two waves of European colonization, the first took place in the late 1490 s to the early 1500 s and the second took place in the 1620s. Wilson illustrates Columbus's sightings of large and dense populations of up to several thousand Carib peoples in the Greater Antilles region in 1492 
(Wilson 2007). Evidently, people of the Greater Antilles suffered the impact of the first wave of European conquest through disease and being enslaved, whereas people of the Lesser Antilles appear to have endured the repercussions of European contact with less difficulty as a result of their mobility and nomadic culture (Wilson 2007). During the first wave of Colonial exploration in the Caribbean, European explorers introduced a series of contagious diseases in 1492. Wilson implies that there could be a relationship between the earlier arrival of Europeans and the decrease in population of the Lesser Antilles (Wilson 1989). From what researchers can determine, the pre-Colonial settlement on Nevis after 1200 CE was periodic (Wilson 2006).

Archaeologists have suggested that Columbus sailed past Nevis in 1493, and journal writings from Columbus states that he saw people canoeing in the distance (Hubbard 1931). Later, in 1585, Sir Francis Drake's fleet stopped in St. Kitts for a few days and, as far as they could tell, neither St. Kitts nor Nevis were inhabited (Wilson 2006). However, in 1606 an English ship landed on Nevis, and George Percy recorded sightings of people "running through the trees" (Barbour 1969), and there is a brief mention in a historic document that suggest there was a small population of Carib on Nevis in 1675 (Hilton 1675). Nevis was not officially settled by the English until the late 1620 s, and according to more recent archaeologists, there were no Caribs living on the island at that point (Wilson 2006). Wilson explains that it is difficult to judge how many indigenous peoples were inhabitants of St. Kitts and Nevis, or when the islands began to be 
colonized, because there is very little historical evidence (Wilson 1989). Merrill (1958) also concluded that at the time of settlement on St. Kitts in 1624, Carib peoples were present on the island in small numbers, but Nevis was unoccupied (Wilson 1989). Oldmixon (1708) discusses how first encounters between Europeans and Caribs on St. Kitts involved the Caribs showing Colonists how to kill large lizards on the island. But Merrill and Wilson discuss how later encounters between Europeans and Caribs were quite barbaric. Historical writings describe massacres and rape perpetrated by the Spanish, and supposedly cannibalism from the indigenous peoples (Merrill 1958; Wilson 2006). However, burial analysis on Nevis does not illustrate any evidence suggesting that the Carib peoples were cannibals (Keith 2014; Morris et al. 2000, 2001, 2002).

\section{Caribbean Culture Literature Review}

Irving Rouse was one of the early archaeologists who began investigating the Caribbean in the 1930s, and his work paved the way for later archaeologists. Much of Rouse's research focuses on migration, settlement, and identification of the timing of each era. One work from 1977 describes how, through ceramic complexes, Rouse discovered that people in the Lesser Antilles migrated from different origins than did the people in Puerto Rico (Rouse 1977).

Rouse $(1951,1961,1977)$ mostly analyzed migration patterns and constructed group categorization. This work began to classify people into different native groups based on the different regions they occupied, including 
the Ciboney, Arawak, and Carib (Rouse 1951). Caribs mostly occupied the Lesser Antilles. Rouse $(1951,1961,1964,1977)$ provided background to what we know today of Caribbean history; specifically, settlement patterns. However, Rouse (1964) specifically discusses the relative and specific time scale of the overall Caribbean history through extensive stratigraphic excavations.

The specific time scales have been estimated through carbon-14 dating (Rouse 1964; Wilson 2006). This technique is expensive enough that very few projects are able to produce more than one or two dates. Most of the archaeological Caribbean projects have taken one or more dates on Nevis or other islands. While Rouse (1951) is one of the few who produced a series of sixty-five carbon-14 dates for analysis in the 1950s, the analysis does not permit conclusions on a specific area because the samples were distributed over a large region, where localized data would be necessary for more specific conclusions. Also, Rouse's dates are from the beginning methods of radiocarbon dating and need to be refined for more accurate results as there is a greater margin of error.

Rouse categorized pre-Colonial people into five periods using the sixty-five dates. The oldest dates included paleo-indians inhabiting western Venezuela around 15,000 BCE, and Caribbean people living in the islands around 5,000 BCE (Rouse 1964). However, a more recent study conducted by Roksandic et al. (2015) states that the earliest inhabitants only date back to about 3,000 BCE. Wilson (2006) also uses the 3,000 BCE date as a reference point.

Merrill (1958) studied the geography of the islands as it looked in the 1950s. 
As did other authors who are reviewed in this section, Merrill compares his data of Nevis's landscape to observations in Colonial literature. Merrill's reports includes detailed analysis that is still useful today when comparing past literature with contemporary observations, because the landscape has changed significantly since the 1950 s.

Wilson $(1989,1993,1997,2006,2007)$ has been conducting research in the Caribbean since the 1980s. He has produced a series of publications that has contributed to unraveling the mystery of prehistoric Caribbean settlement, specifically in Nevis. Of his many publications, only two refer to Nevis, where the others are generalized Caribbean history. The first is Wilson (1989), in which he first began describing exploration of the Leeward Islands in the late 1980s. Wilson discusses a large population growth from the Saladoid to Ostionoid sites in the overall area of the West Indies (Wilson 1989). This discussion connects many works from Caribbean researchers on how the ceramic analysis and specific cultural changes indicate the difference from the early to Late Ceramic Era (Keegan 2000; Rouse 1991, 1961, 1964; Wilson 2006, 2007).

The predominant source from Wilson (2006) gives a comprehensive analysis and discussion of the pre-Colonial era of Nevis. Wilson's work specifically relates to my research because he originally documented the shell midden scatter that became the 2016 SJSU field school. A large portion of that book focused on ceramic analysis. However, Wilson also provides a thorough literature review of Colonial writings and includes chapters written by colleagues who were involved 
with the fieldwork, illustrating different aspects of the paleoethnobotanical analysis that have been compared to the results of this thesis's findings.

Wilson's interpretations of Nevis's history explain how the island went through several major changes that have been reflected in the cultural material objects.

The most obvious transition was illustrated by the change in pottery patterns from the Early to Late Ceramic period. The transitions in pottery patterns have been observed and discussed by multiple researchers, but my thesis will focus only on three (Keegan 2000; Rouse 1961, 1964, 1991; Wilson 2006, 2007). Two of these authors interpreted the later transitions in pottery patterns to represent the work of different peoples.

I agree with Wilson that there is a stronger possibility these populations were the same people representing evolving societies. There are strong correlations that have been discussed regarding the population growth and increasing number of Ceramic Age sites in the Caribbean. Keegan (2000), Rouse (1961, 1964, 1991), and Wilson (2006), have all speculated how the increase of sites could be related to either significant population increase or the sophistication of trade/travel routes. Based on the progression of the Caribbean trade routes, there is a stronger probability that Caribs on Nevis were adopting newer painting techniques in addition to population growth, rather than different people inhabiting the island.

Wilson also reports on the settlement patterns of the island and the possible scenario of why people may have been leaving the island shortly before the 
period of Europeans. According to Wilson's spatial analysis, the windward settlement pattern could be related to the natural resources being utilized. For example, resource utilization could have included shellfish collection and reef fishing (Wilson 2006). Then Wilson argues further that, if the Caribs had exhausted their resources on Nevis, it could have driven them elsewhere (Wilson 2006).

Keegan is another Caribbean archaeologist who has not specifically done research on Nevis but has done extensive research in the West Indies regarding pre-Colonial peoples. Out of all his publications, three have been most influential to my thesis project (Keegan 1994, 2000, 2017). These articles give specific analysis from multiple sources (Irving Rouse, Louis Allaire, and David Watters) regarding the geography of the West Indies, chronological and cultural systems, and a detailed review of each ceramic phase.

In these works, Keegan's arguments parallel those of researchers like Rouse and Wilson, emphasizing that there was a dramatic change from the early to Late Ceramic period (Keegan 2000). Keegan proposes this change could be due to the presence of different people (Keegan 1994). One primary foci of my thesis is exploring whether we can identify this change through sediment analysis. Keegan's hypothesis suggests that the cause of a significant cultural change could be related to people abandoning the island in the Early Ceramic and different people living on the island during the Late Ceramic period (Keegan 2000). However, this abandonment hypothesis is not supported at this time, with 
the recent skeletal dating of SJSU field research dating human remains on the island 700 years ago (Personal Communication Meniketti). There is a very strong possibility that people in this region carried on a dynamic and mobile lifestyle due to the geography and ecology of the island region. Currently there is no research that supports the theory of Nevis being abandoned just before the European settlement.

While there has been a deep exploration of settlement patterns in the Caribbean, there have only been a few research projects that directly pertain to the SJSU Field School of 2016 site on Nevis. From 2000 to 2002, The Nevis Heritage Project (NHP), conducted by Southampton University, surveyed landscapes and excavated a pre-Colonial village site in the Whites Bay area (approximately 500 m south of SJSU's shell midden). Southampton's research focused on three Late Ceramic "Ostionoid" Era sites that had not been mentioned in Wilson's (2006) earlier surveys. Of these three sites, the NHP evaluated pottery, which confirmed earlier allegations regarding different phases of ceramics predicted by this recurring idea of a "culture change."

The other research project that directly relates to SJSU's 2016 site includes Chris Keith's thesis (2014). Keith (2014) describes a find of prehistoric human remains from a site near SJSU's 2016 research site and Southampton's sites. Keith's research is relevant to this project because the remains described belong to prehistoric Carib populations who lived in the Late Ceramic village and were affiliated with the shell midden studied in the summer of 2016. The skeleton 
dated by Keith was about $1050 \mathrm{CE}$, and based on the analysis of one tooth, the remains revealed a diet and lifestyle that contributes to the overall reconstruction of prehistoric Nevis. For example, Keith explains that the evidence of wear on the dentition indicates high levels of attrition and carious lesions coming from stone ground maize or other complex carbohydrates.

The skeletons dated by SJSU in 2016 (Meniketti, personal communication), have provided similar dates around 700-900 years ago, but just slightly younger than Keith's find in 2014. Both of these dated remains inform archaeologists that Nevis was not deserted after $500 \mathrm{CE}$, and there were in fact people living on the island. This information is contrary to previous suggestions by Keegan (1994, 2000) and other archaeologists (Morris et al. 2002; Wilson 2006) stating that Caribs on Nevis had disappeared before 1,000 years ago. Furthermore, these data suggest that Nevis was most likely experiencing Carib settlement leading up to the first wave of Colonial explorer's. I am hoping the research from this thesis is going to build on the evidence from recent skeletal analysis by providing data to improve upon our knowledge of Nevis's paleoenvironment, and suggest new explanations regarding the Late Ceramic cultural change analyzed by so many researchers.

The next chapter will describe the methodology that influenced the applied methods in my research. For example, I dug a test pit to expose the stratigraphy so I could examine patterns and collect sediment samples from each horizon. Because my thesis focuses on sediment analysis, many of these methodologies 
are based on foundational geologic concepts and theories that directly relate to the excavation methods, collection process, observations recorded in the field, and methods conducted in the lab. 


\section{CHAPTER 4: Methodology}

Introduction

Archaeologists frequently apply interdisciplinary concepts to strengthen research methodology. Archaeology is a discipline greatly influenced by geologic and ecological theory. These scientific theories are driven by physical observations and supported by experiments. Geoarchaeology is the field that encompasses the application of the earth sciences to the archaeological field (Rapp and Hill 2006). In this chapter, I review theoretical concepts that have influenced the field methods and laboratory procedures presented in this thesis.

Landscape formation is an important factor pertaining to this research. Landscapes are geological formations, but cultural landscapes are those that embody human histories (David and Thomas 2008; Kvamme 2003). These cultural histories have been embedded into the geological landscape and can sometimes be read as if they were pages of a book. Scientists cannot separate people from the environments. Landscape is an entangled term in archaeology, geography, geomorphology, and ecology, because it retains physical evidence of history, which we then use to understand the past, the contemporary, or the potential future (Crumley and Hornborg 2007; David and Thomas 2008). If an environment has been significantly influenced by humans, a through analysis of the landscape can inform archaeologists how the population constructed and interacted with the environment.

The analysis of the SJSU Nevis 2016 Field School shell midden site includes 
an investigation for patterns in the stratigraphy of one of the trenches $(1 \mathrm{~m} \times 2 \mathrm{~m} \times$ $120 \mathrm{~cm}$ test pit) for any evidence of cultural influence on the shell midden landscape. Nevis, for example, has a history of different peoples inhabiting the island in the last 3000 years. This, coupled with the fact that Nevis has an eroding coastline, makes the story difficult to unravel. By utilizing concepts from the geological and earth sciences, we are able to draw conclusions about the soil- and site-forming processes based on the well-developed theoretical constructs given by the aforementioned fields.

In general, a landscape's vegetation and soil patterns are reflected by geologic and geomorphological processes (Goldberg et al. 2001; Goldberg and Macphail 2006; Hassan 1979). Geomorphology is a field that analyzes landscapes, their processes, and the formation of sediments on the surface of the Earth (British Society for Geomorphology 2017). Specifically, the geomorphological processes define weathering and formation of soils, sediment transport, landscape change, and interactions between climate, tectonics, erosion, and deposition (Bird 2011; Goldberg et al. 2001). The concepts of geomorphology can be directly applied to Nevis due to the intensity of its active coastal areas, and explored through the application of sediment and soil analysis.

Sediment and soil are distinct and are formed by two different processes. Sediments have dynamic histories; they are eroded, transported, and deposited over a landscape (Goldberg and Macphail 2006; Hassan 1978). In contrast, soils 
are a type of material that forms in situ through weathering or biological processes and usually contains more organic material (Goldberg and Macphail 2006). Determining the difference between these two materials is critical for interpreting a landscape's past.

Sediment develops through the processes of weathering, erosion, and transportation before it begins to form structured stratigraphy (Goldberg and Macphail 2006; Hassan 1978). Geoarchaeologists can discover this dynamic history by applying concepts of geomorphology. Further investigation of sediment leads to examining the principles of sedimentology, the study of sediments, which include sand, silt, and clay, and the processes that result in their formation (Goldberg and Macphail 2006; Hassan 1978). Sediment analysis will be used to interpret the geologic history of the field site studied here through observations and laboratory testing.

The field book that has been most influential in guiding my field and laboratory methods and shaping the theoretical and practical aspects of this project is Goldberg and Macphail (2006). This is a general handbook for archaeologists pursuing research in the geological field, and provides detailed descriptions of methods. Fekri A. Hassan is another primary geoarchaeologist from the 1970s and 1980s whose work has influenced this interdisciplinary study of archaeology and geology. Hassan (1979) explains methods relating to the analysis of sediments for the elucidation of site-forming processes, the quantification of microarchaeological remains, and the analysis of 
paleoenvironments. These methods are similar to those used by other researchers who specialize in geoarchaeology. However, I have found it helpful to compare various works for a better understanding of what methods would be more applicable to these research questions.

In addition to studying the evolving sediments, a complete landscape analysis requires a thorough inspection of the pedological process. Pedology is the study of soils and soil formation in their natural environment (Goldberg and Macphail 2006). These formation processes can be represented by the following formula:

$$
s=f(C L, O, R, P, T)
$$

Here, $s$ represents soil properties as a function $f$ with respect to the soil forming factors. These factors are broken into the arguments. They are as follows: $\mathrm{CL}$ denotes climate, $\mathrm{O}$ stands for organisms, $\mathrm{R}$ constitutes a general term "relief" that portrays landscape features formed from a downslope accumulation of eroded rock or soil, $\mathrm{P}$ is the parent material, and $\mathrm{T}$ is time (Goldberg and Macphail 2006; Jenny 1941). This qualitative function provides a foundation for analysis and reconstruction of past landscapes. Keeping this function in mind, I examined the factors that contribute to the soil formation.

Sediment and soil settle in layers which are observed by geoarchaeologists. The layering pattern beneath the surface of the ground is called substratum, and in practice, sediment and soil is profiled into "horizons." These horizons are labeled as follows: A (or 1 ) is the humose topsoil horizon, $\mathrm{B}$ (or 2 ) is the pedologically formed subsoil horizon, C (or 3) is the horizon or weathered parent 
material, and D (4 or $\mathrm{R}$ ) is the horizon of consolidated bedrock (Goldberg and Macphail 2006). The A and B Horizons are generally constructed via soil-forming processes, $s$, and are relevant for archaeological research. Some sites can contain horizons that illustrate multiple processes, including sediments transferring and settling. Soil-forming processes take place, where certain organic material begins to break down from chemical weathering. In many cases of archaeological site-forming processes, there is not one clear procedure but multiple ones.

In the field, excavators can categorize horizons by labeling them as they differ in grain size, color, and texture. Determining whether the stratigraphy is profiled into soil and or sediments is crucial early in the research, because different laboratory methods are used in each case. Pedological procedures utilized include identification of sediment texture and colors, and comparing these descriptions to the horizons above and below (Goldberg et al. 2001; Prothero and Schwab 2014; Righter 1991). The textures of sediments are determined by the grain size, size variation, roundness, surface features, and overall composition (Hassan 1978; Prothero and Schwab 2014). After two test pits were excavated, the horizons were first determined by differentiating layers of different color. Sediment colors were described using a 2000 edition Munsell color chart from Gretag Macbeth publishing.

Grain size analysis, or particle size analysis, is a method conducted in geoarchaeology and pedology studies. Grain size is determined by particle 
diameter and can be measured using sieve size analysis (Prothero and Schwab 2014). This procedure may give information related to the energy of deposition and the environment of deposition that has constructed the sediment layers (Goldberg et al. 2001; Goldberg and Macphail 2006). The homogeneity of a horizon, or lack thereof, can tell us how the sediment was transported (Goldberg and Macphail 2006). There can be more than one parent material and multiple depositional processes, making horizon interpretation more involved.

Through grain size analysis, four different standard categories of grain sizes can be recognized (Goldberg and Macphail 2006; Prothero and Schwab 2014; Righter 1991):

1. Gravel $>2000 \mu \mathrm{m}$

2. Sand $63-2000 \mu \mathrm{m}$

3. Silt $\quad 4-63 \mu \mathrm{m}$

4. Clay $<4 \mu \mathrm{m}$

This thesis explores a sediment analysis centered on a shell midden. We are interested in the environmental history of the pre-Colonial landscape and how this midden became an archaeological site through exploring the application of sediment analysis and theoretical concepts of site formation. The test pits dug for this study portrayed at least two depositional processes. For example, one deposition process could include wind deposited material. For the purposes of this project, I analyzed the sedimentary characteristics of the shell midden site to determine whether or not the formation and transportation of sediments provide 
any evidence of an abrupt cultural change between the pre-Ceramic and the Late Ceramic period.

Grain size analysis is used to determine relative proportions of sand and fine sediment, and of clay and silt. Most environmental reconstructions rely on determining the proportion of clay with respect to the rest of the material (Goldberg and Macphail 2006). Because clay is sediment that is formed in part by the weathering of larger rocks (Prothero and Schwab 2014), soils with higher percentages of clay have been weathering longer or under harsher circumstances or else the clay has been transported here separately. Horizons that contain higher clay content may also imply wetter climatic conditions (Goldberg and Macphail 2006). For example, higher percentages of clay can implicate wetter environments or landscapes experiencing more severe weathering processes, whereas horizons with lower clay content usually illustrate environments with a drier climate (Goldberg and Macphail 2006).

Middens usually provide evidence of landscape patterns that allude to how humans use their environment (Wilson 2006). One of the primary benefits of excavating shell middens is that shell material produces high levels of calcium carbonate, which effectively raises the $\mathrm{pH}$ of the middens (Ambrose 1967). This alkaline state slows the normal rate of decay, thus leaving a higher proportion of organic material, including food remnants, organic tools, clothing, and human remains (Ambrose 1967). Through analyzing compositions of sediment and patterns of soil, archaeologists can reconstruct the formation history of shell 
middens. However, the SJSU shell midden on Nevis has been experiencing extreme chemical and physical weathering. Normally, shell middens would appear in mounds of piled up shell and discarded debris. The most applicable theoretical concept that can be applied here is vertical conflation. Conflated materials occur when artifacts from different soil horizons combine, appearing as one horizon (Fanning and Holdaway 2001; Shavitt et.al. 2006).

Regarding the SJSU midden, there appear to be horizons missing from the stratigraphy and the midden material, and artifacts have been condensed. We know this area has experienced loss of topsoil from the colonial repercussions of the sugar plantations, and this particular side of the island used to have a road that was graded and then paved with cobble stones on top of these archaeological sites (Meniketti 2015). Vertical conflation involves the top soil washing down the slopes, but the larger artifacts that are heavier than soil stay in situ and become vertically concentrated (Fanning and Holdaway 2001; Shavitt et.al. 2006). As a result of the impacts of the historical road construction and weathering conditions, the midden today appears more as scattered shells than a mound.

\section{Recovery Methods}

The study of the Whites Bay site (Figure 8) was conducted by the SJSU Field School in the summer of 2016. This project was directed by Dr. Marco Meniketti, with San Jose State Masters student Marissa Massaro as crew supervisor, and myself as crew chief. Both Massaro and I had prior experience in archaeological 
excavation. Before arrival on Nevis, I was not sure what to expect because it was my first time visiting the site, as well as the island.

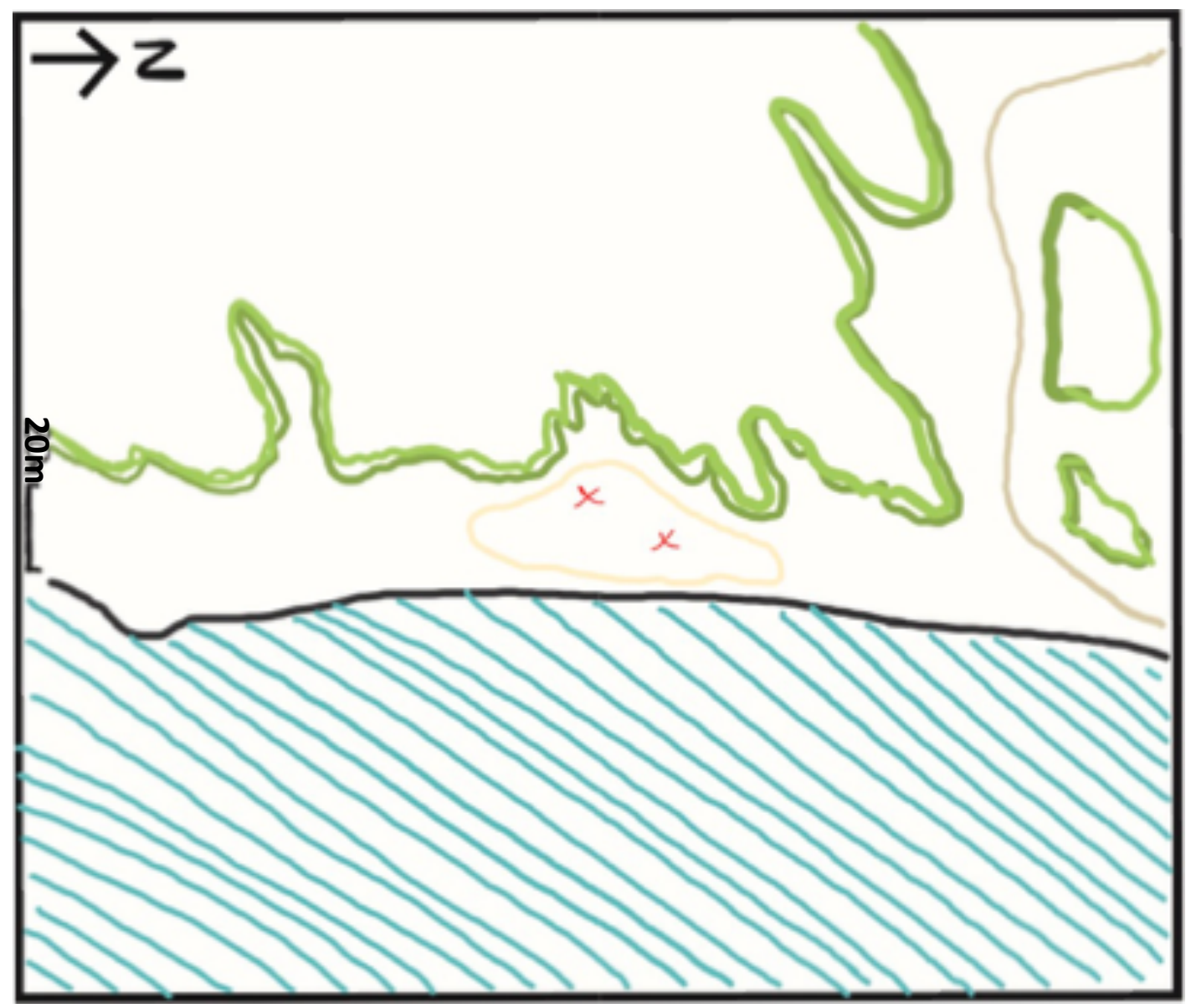

Figure 8. Sketch of shell midden site. T1 is north of T2, marked by red x's.

The methods used for this reconstruction were shaped by the overall field dynamics of the larger project. The applied field methods included photography (Figure 9), drawing, note-taking, observation, excavation, and soil sampling. This chapter will explain why we chose the location of the two test pits, the processes of the excavation, and the sampling strategy. 


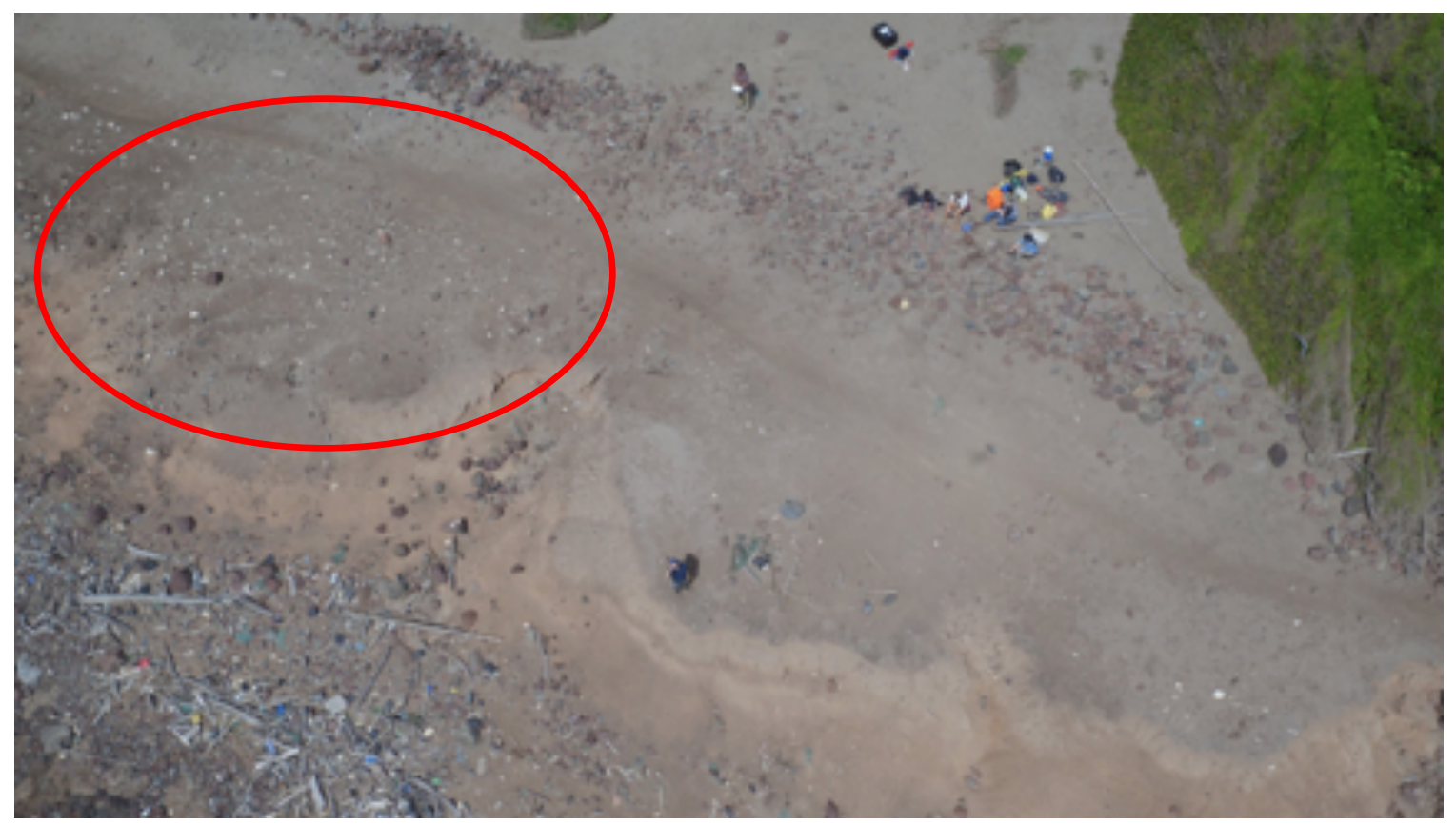

Figure 9. Aerial photograph of shell midden scatters (circled in red) before excavation, and crew pictured sitting (Photo by Tim Rodriguez and used with permission).

At the inception of the fieldwork, the project leaders chose the location for the first test pit "Trench 1" (T1) (Figure 10), a unit $2 \mathrm{~m} \times 1 \mathrm{~m} \times 120 \mathrm{~cm}$. At this specific location, we decided to cut into a slope at the edge of the midden (Figure 11). The tools used included shovels, trowels, and a mesh screen for sifting soils. Surface artifacts were drawn, and occasional artifacts consisting of shell, ceramics, and one non-human bone were found in the stratigraphy. However, the $10 \mathrm{~cm}$ recording levels were not recorded as per normal archaeology unit excavation because the interest was the end stratigraphy. When the excavation of T1 was finished, the findings were inconclusive. We realized this area contained material that had eroded down from the hillside, and a second test pit (T2) needed to be examined. 


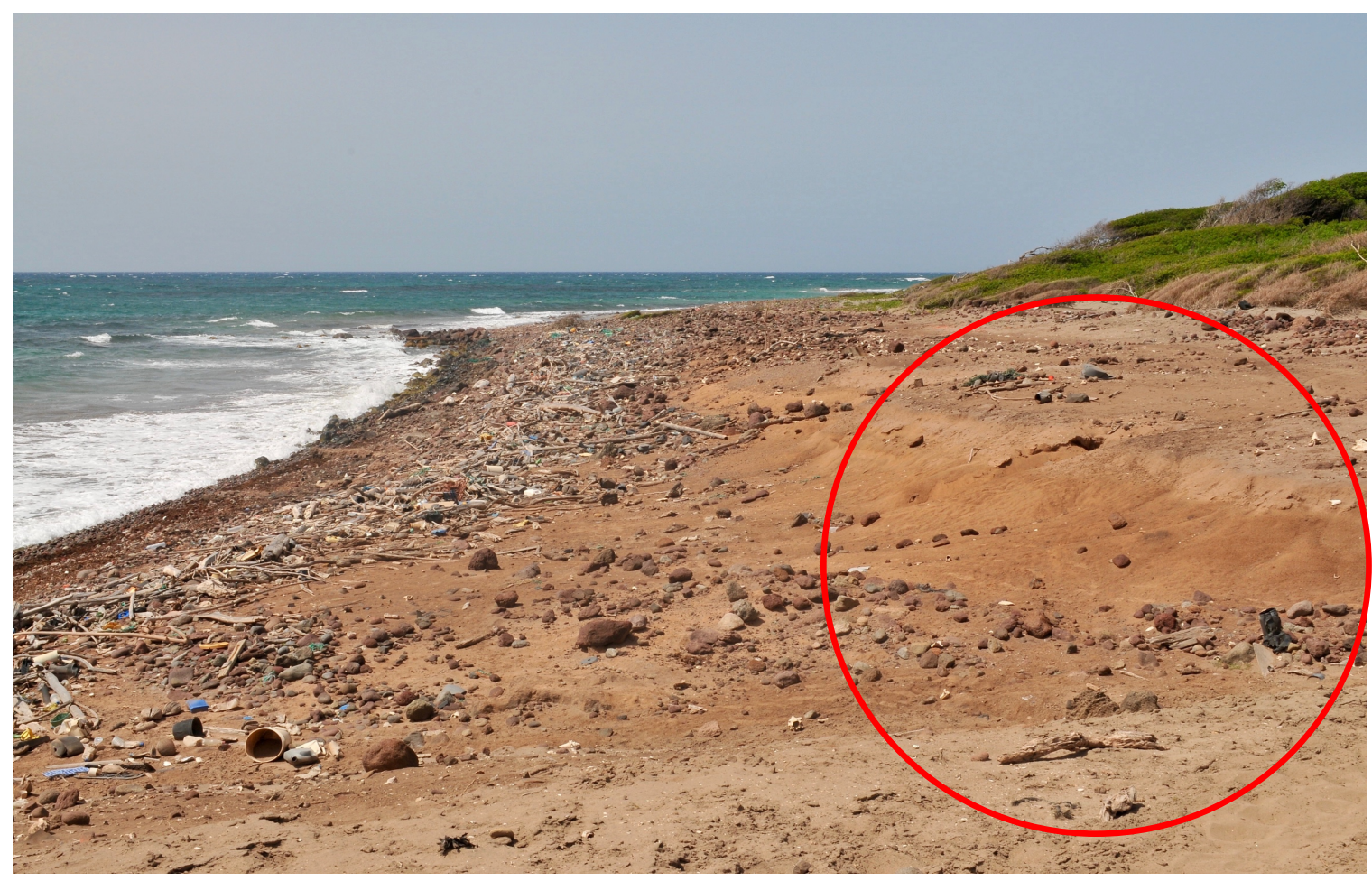

Figure 10. Shell midden scatters pre-excavation, looking south (Photo by author).

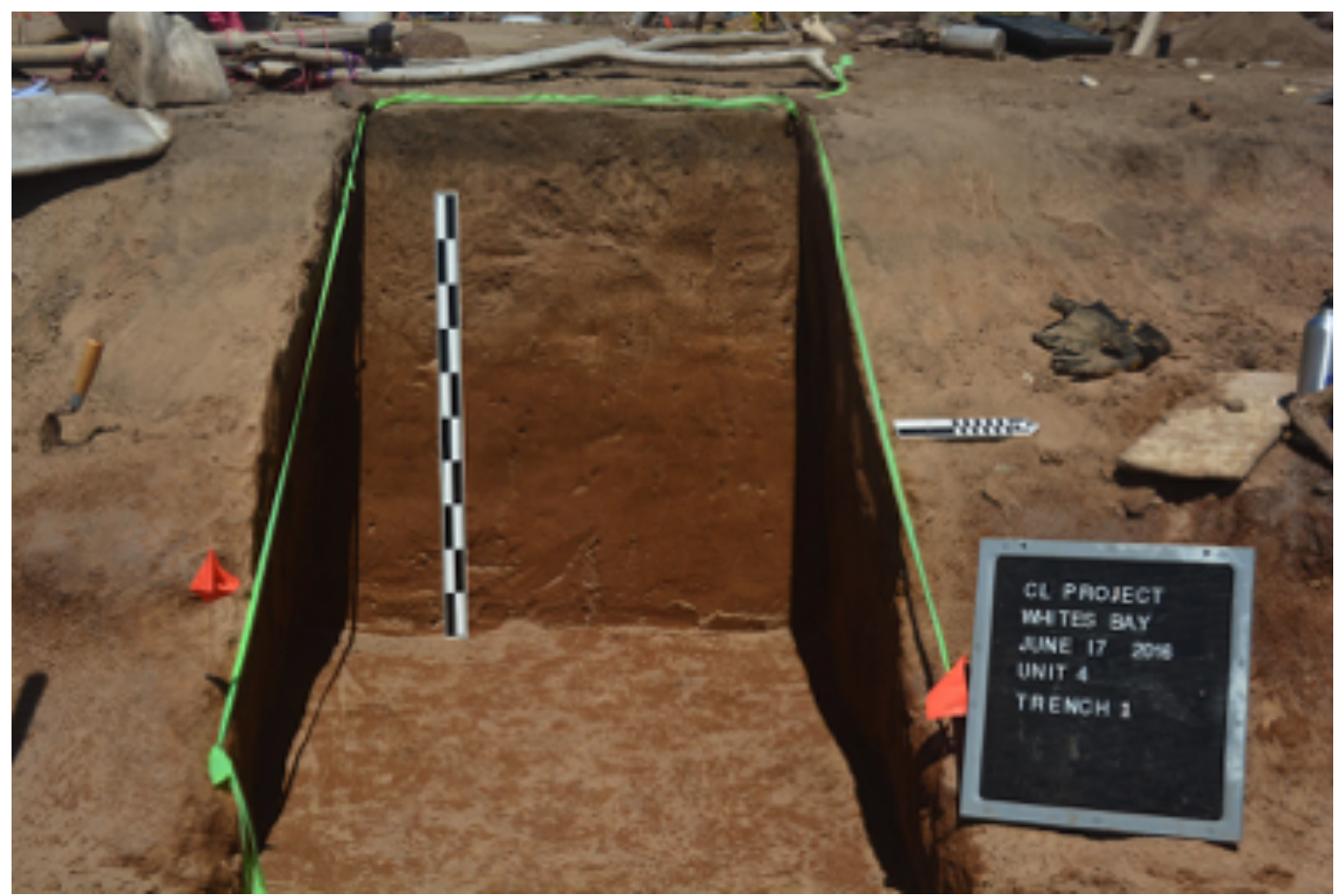

Figure 11. Trench 1 post excavation. No obvious stratigraphy (Photo by Meniketti and used with permission). 
T2 was placed more centrally in the shell midden and was twice the volume of T1, $2 \mathrm{~m} \times 1 \mathrm{~m} \times 160 \mathrm{~cm}$ (Figure 12, 13, and 14). Due to the limited duration of the project, T2 was dug very quickly in order to be completed within the allotted time. However, the concrete solidification of Horizon 1 required different tools than were used in T1, including a large pickaxe, shovels, trowels, and a Chisel-edge rock hammer. There was limited recording of ceramics once the surface sketch was finished, because the goal of this unit was to record geologic data, including sediment forming processes. However, no cultural material was noted below the top horizon.

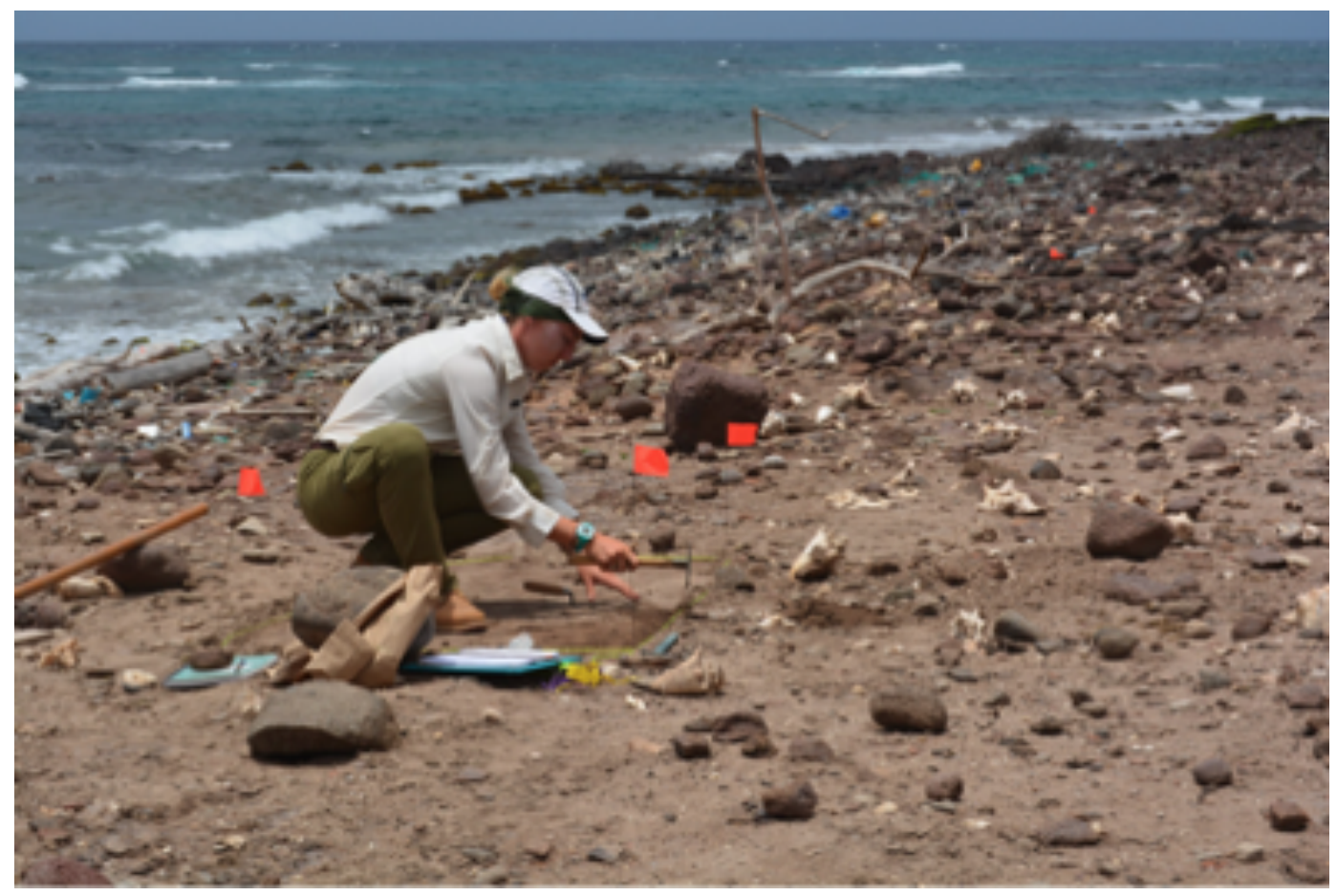

Figure 12. Trench 2 pre-excavation, looking South (Photo by Meniketti and used with permission). 


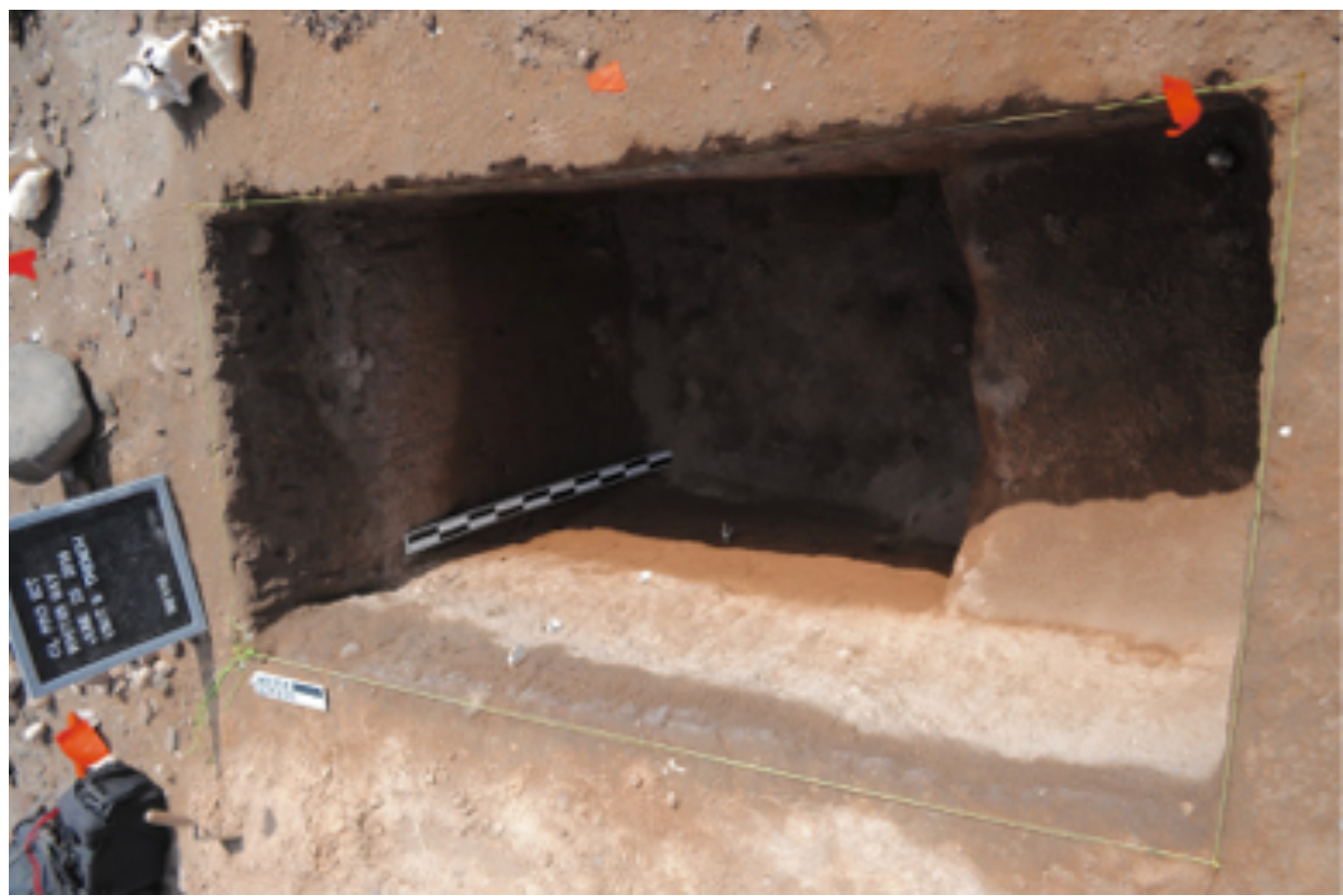

Figure 13. Trench 2 post excavation (Photo by author).

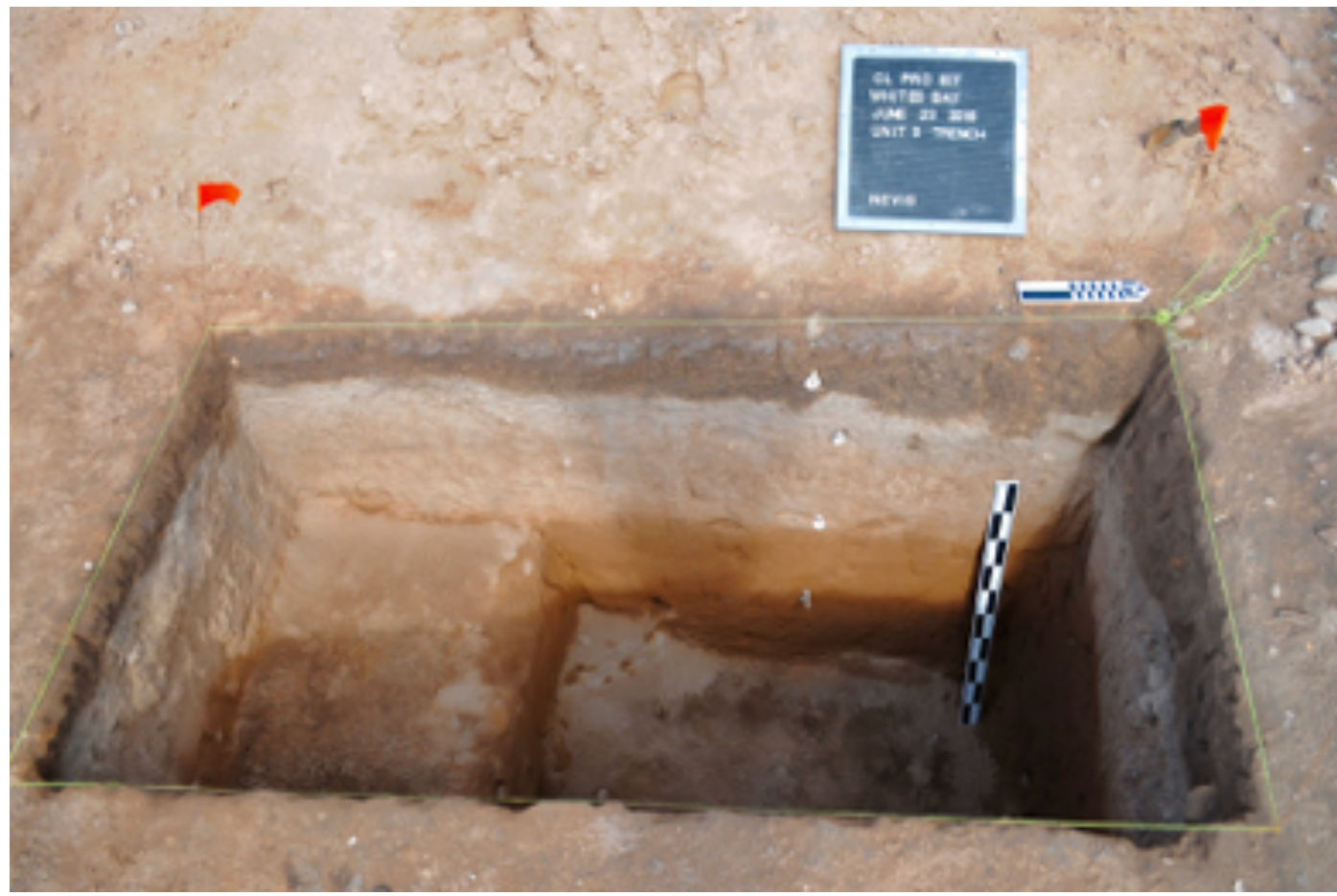

Figure 14. Trench 2 after excavation, west wall and meter stick pictured (Photo by author). 
Photography and drawings were used to document each of the four horizons of T2. Then a random sampling technique was applied to each of the 4 labeled horizons. Three random samples were collected from each of Horizons 1 and 2, because these layers would more likely be related to the cultural timeline, whereas only two samples were collected from each of Horizons 3 and 4. Cultural horizons are layers in the sediment stratigraphy that include culturally related items and give archaeologists a relative timeline in relation to the soil formation. For example, if the top Horizon 1 is the only layer that includes culturally related material, then archaeologists can assume that the occupation of humans was brief and/or recent compared to the history of soil or sediment formation (Goldberg and Macphail 2006).

\section{Laboratory Procedures}

The laboratory method chosen for sediment characterization was grain size analysis of each horizon from T2. The sediment characterizations depict what the horizons are generally composed of by looking at sediments under a microscope, analyzing each horizon's color, and shape of grains. However, the bulk of time spent in the laboratory was used to determine the grain size distributions from each horizon of T2.

In order to determine the grain size distribution that will characterize the percentages of sand, silt, and clay there is a series of first wet and dry sediment sieving. The wet sieving process begins by carefully extracting about $1 / 4$ of a sample from each horizon and placing these extractions in beakers. The next 
step involved breaking up the aggregates, which have been glued together by mud, and separating the clay and silt (mud) from sand grains and other material. In order to break up these aggregates, an ultrasonic bath was used because the clay was glued to the sand grains.

Samples were placed in water with $25 \mathrm{ml}$ of $\left(\mathrm{NaPO}_{3}\right)_{6}$ (sodium hexametaphosphate), commonly known as water softener, and was placed in a freezer overnight. I began to see better results with the addition of water softener to the samples. After thawing, samples were placed in an ultrasonic bath to further break up aggregates. These combined processes provided much better results. The mud was then separated by pouring it through a $63 \mu \mathrm{m}$ sieve. This process separates the sand from the silt and clay. As soon as the sediments have separated, the clean sand was baked at $95^{\circ} \mathrm{F}$ to dry (Figure 15 ), and the container of mud was moved to a graduated cylinder for processing.

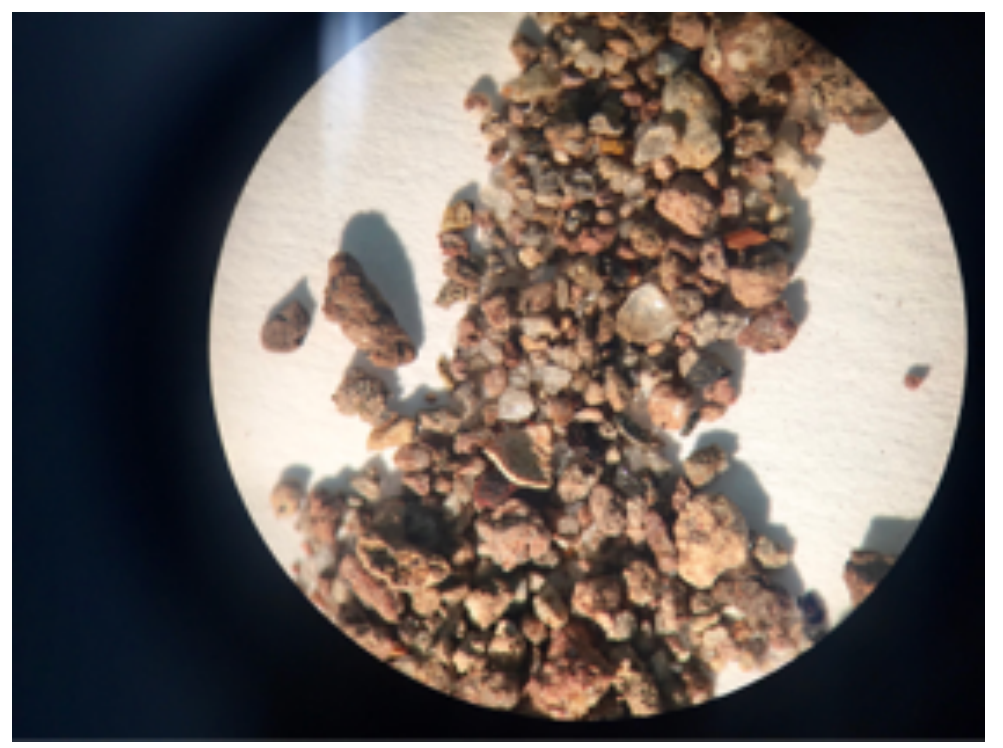

Figure 15. Sediment from $\mathrm{H} 1$ under the microscope, after the first wash of wet sieving (Photo by author). 
Stokes Law describes the rate at which sediments settle (Prothero and Schwab 2014). More specifically, sediments sink in water due to gravitational pull. The rate of sinkage is determined by particle size and can be calculated by Stokes law of settling (Prothero and Schwab 2014). This law will determine the clay and silt settling times utilized by the pipette and sedigraph methods.

The beaker of muddy water that was previously collected from the wet sieving process was poured into a 1 liter graduated cylinder (Figure 16), then stirred to mix the sediments. Using a pipette at $20 \mathrm{~cm}$ deep after twenty seconds, $25 \mathrm{ml}$ of liquid was extracted and put in a separate beaker, which was then placed in an oven to dry.

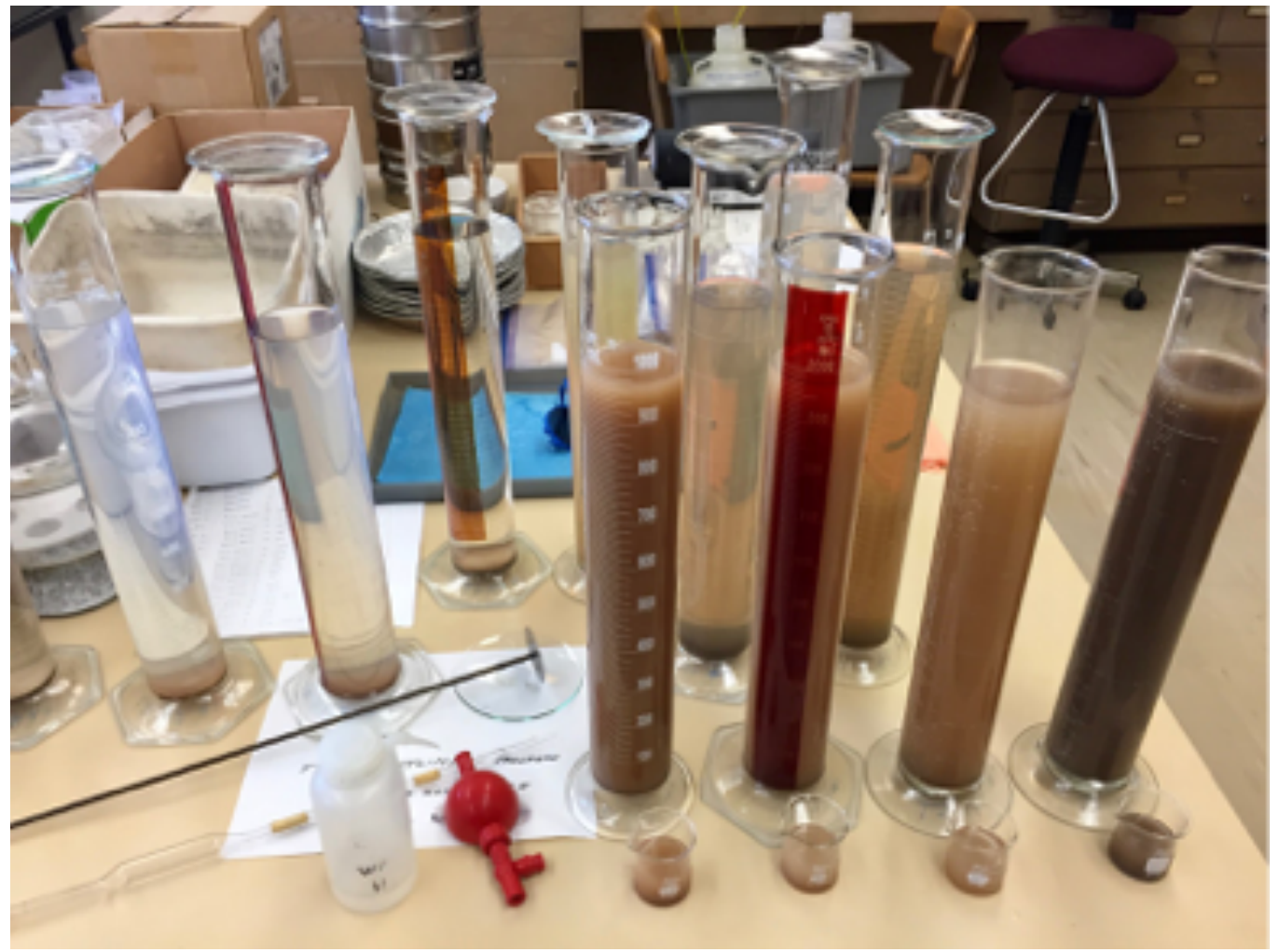

Figure 16. Clay and silt separation using pipette method (Photo by author). 
Because all clay and silt are in this aliquot in their original proportion in the sample, the $25 \mathrm{ml}$ is $1 / 40$ of all clay and silt in the graduated cylinder. This process was used to determine the ratio of fine sediment to sand for each horizon. Once the ratio of fine sediment to sand and gravel has been determined, the samples can then be prepped for the SediGraph machine (Figure 17). The SediGraph is used to measure the particle-size distribution of the clay and silt by shooting x-rays through the sample. Tests were run on each of the horizons and used for further environmental interpretation.

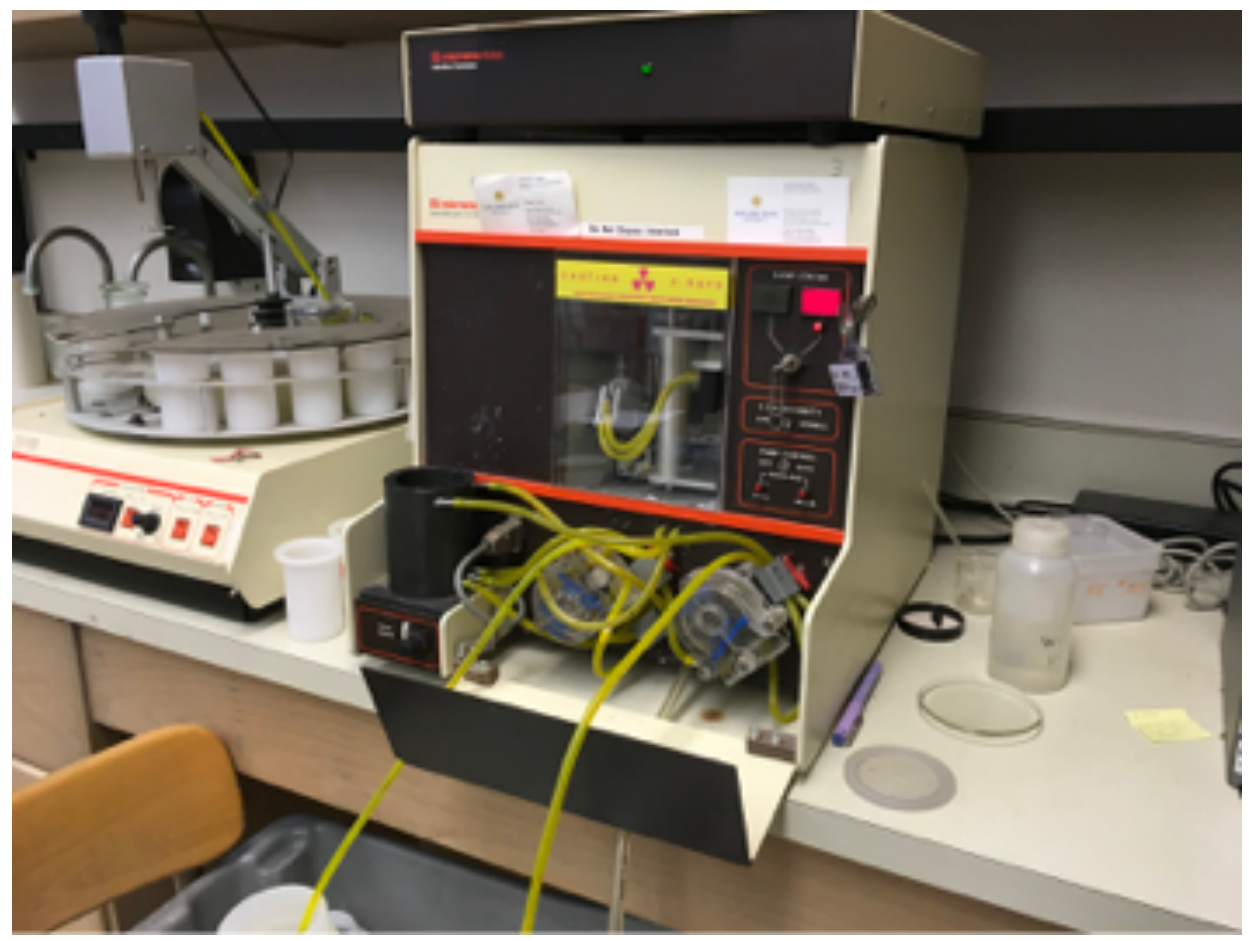

Figure 17. SediGraph machine (Photo by author).

After wet sieving, the sand and gravel were oven-dried and sieved through twenty-five different sieves with sizes from $4 \mathrm{~mm}$ to $63 \mu \mathrm{m}$ (Figure 18). 


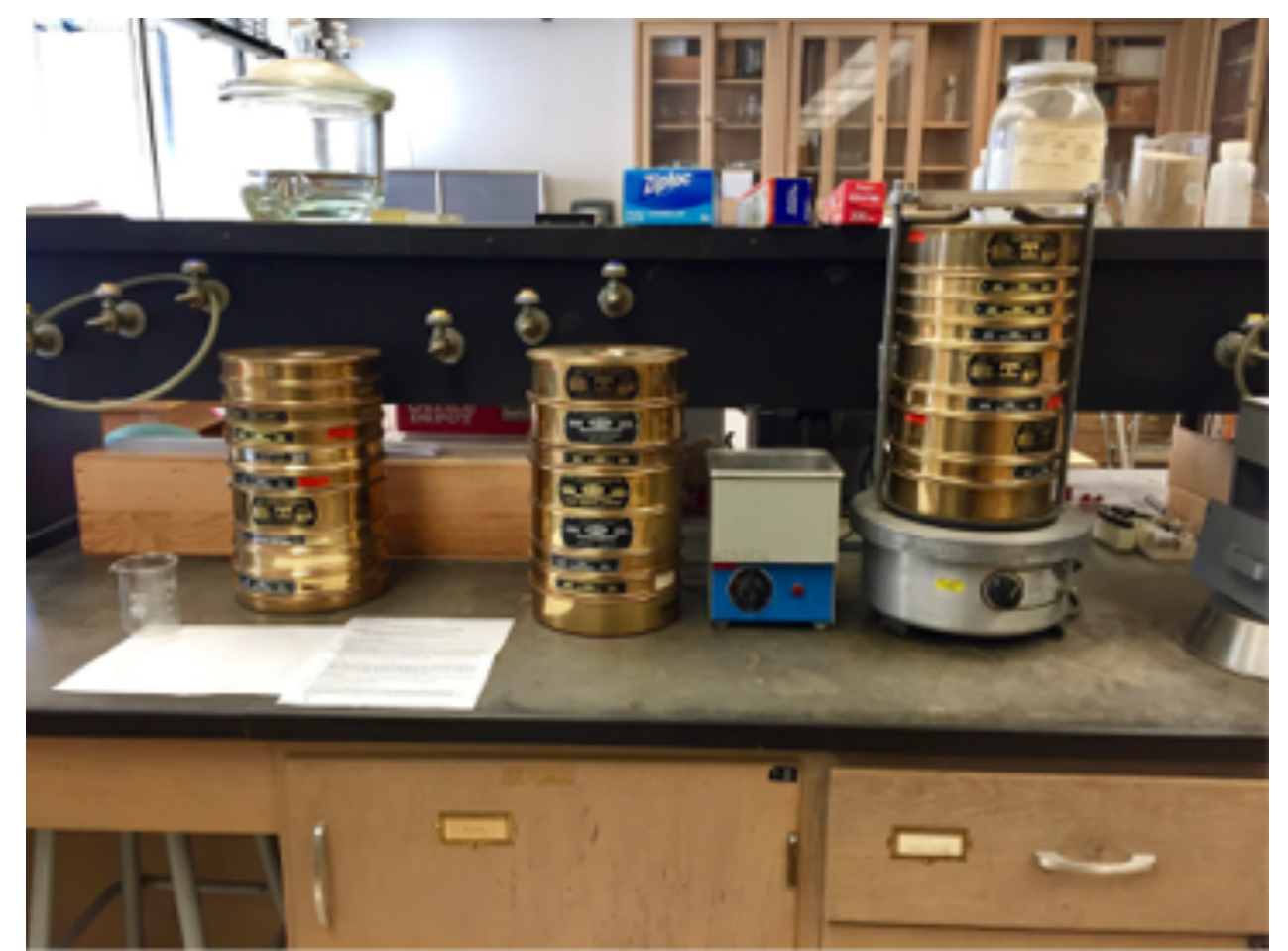

Figure 18. Dry sieve techniques with brass sieves (Photo by author).

Any sediment that fell through the $63 \mu \mathrm{m}$ sieve was added to the clay and silt.

Sediment from each sieve was weighed and recorded to later calculate the distribution of the sand and gravel. Despite the small sample size, the distribution from the samples taken from Nevis was approximately normal.

In the next chapter, I further explain how the results from the SediGraph and sieving techniques are made relevant to the midden itself. A large portion of this sediment analysis involved making connections of the grain size distributions and field analysis to the overall picture. Spatial analysis is a concept and a technique of geographical analysis that illustrates patterns in landscapes and explains how they can be related to human behavior.

Nevis's landscape has changed significantly from the preindustrial era. In 
chapter 5, I discuss the results of the lab analysis. Then I illustrate how the images generated from the results connect the lab data to the site visually, because returning to the site was not feasible. I completed this process by imputing the data into line graphs and histograms, then with the help of Google maps and aerial photos taken by a remote controlled aircraft in the field, a strong visual was obtained showing how the midden appeared. 


\section{CHAPTER 5: FINDINGS}

Nevis's environment has undergone multiple alterations since Colonial contact, and these changes have influenced site formation processes of the shell midden. The data lead to a suggestion of multiple depositional processes and formations of sediments and soils. After T1 excavation yielded lack of horizons, the second test pit was scouted and dug. T2 yielded four distinct horizons that distinguished multiple histories of the paleo sediment for this site. The midden deposit is characterized as a dynamic retreating coastline that is changing on a daily basis. This chapter includes the results from my methods explained from the previous chapter. This section begins with the results that include an individual description of all four horizons. The second part of this chapter contains an interpretation and discussion of how the quantitative analyses illustrates the site formation processes of the Whites Bay Beach Shell Midden. Results

This particular shell midden site has been compacted or eroded into about $20-30 \mathrm{~cm}$ of condensed material due to tilling of the British historic road and years of vertical conflation. The photographs of T2 portrayed boundaries that were distinguished by sharp color changes with curved line boundaries (Figure 19 and 20). The descriptions are as follows: Horizon 4, the darkest and oldest layer, is reddish brown in color (5YR 4/3) and about $70 \mathrm{~cm}$ thick. In the field, a fine sandy and clay texture was observed with many boulders and smaller rocks mixed in. The texture in Horizon 3 is fine sand with no large rocks, and the 
horizon is a yellowish red color (5YR 4/6) about $30 \mathrm{~cm}$ thick.

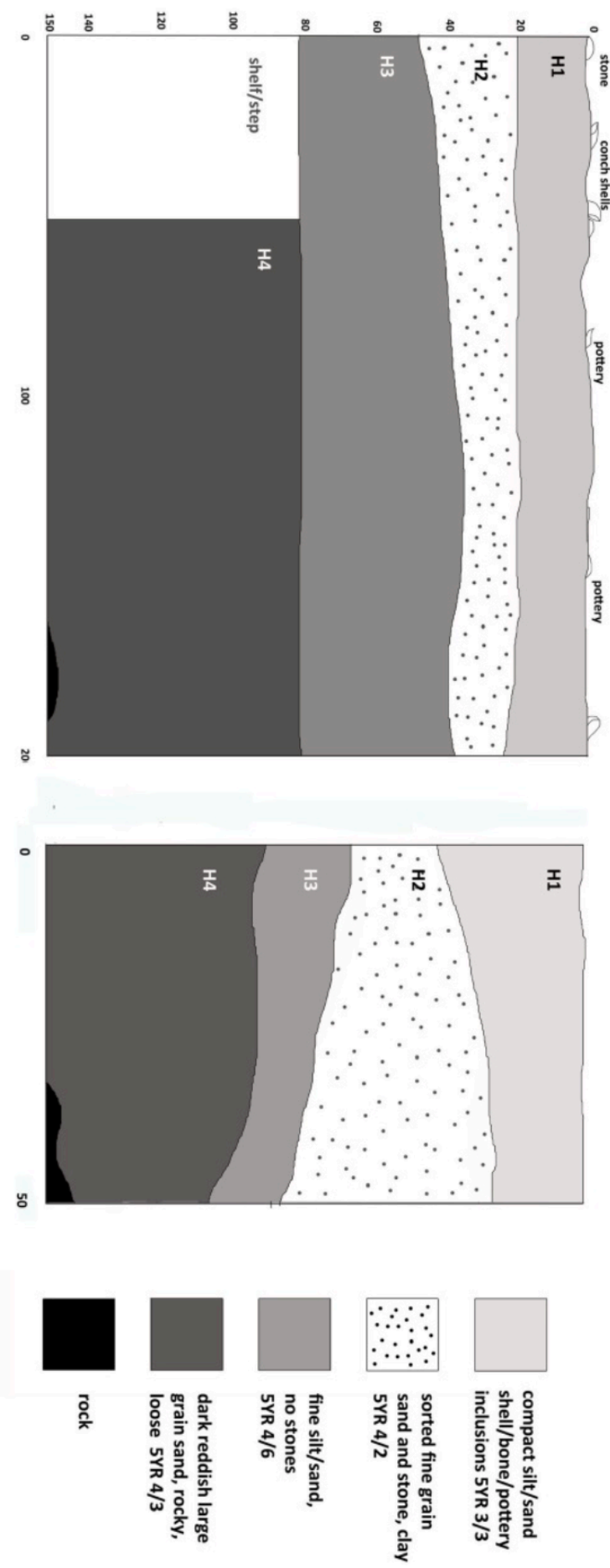

Figure 19. Drawings of Trench 2 post-excavation. Image on the left is the west profile of $\mathrm{T} 2$, and the north profile is on the right. 


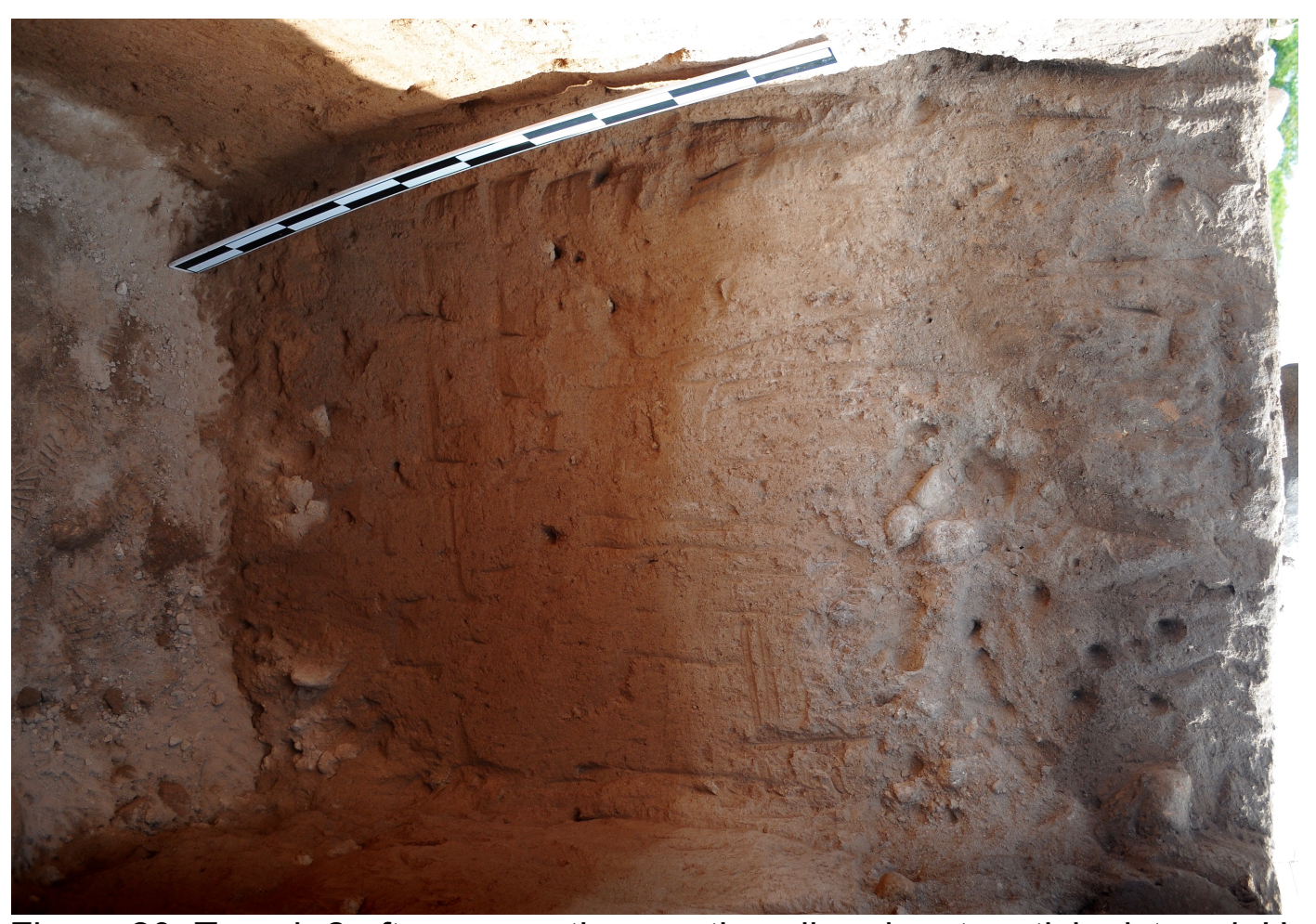

Figure 20. Trench 2 after excavation, north wall and meter stick pictured. Here we can see 4 clear stratigraphic layers.

Closer to the surface, Horizon 2 is a dark reddish grey color (5YR 4/2), which consists of courser sand, and is about $25 \mathrm{~cm}$ thick. Horizon 1, right below the surface, is dark reddish brown (5YR 3/3) and contains condensed anthropogenic material including shell, bone, charcoal, and pottery in clayey course sand. This layer could only be penetrated by using a pickaxe because it was cemented together by clay and calcium carbonate, and was about $10-20 \mathrm{~cm}$ thick.

Horizon 1 represents a composition where shells have been decomposing from chemical weathering processes. The calcium carbonate has begun to accumulate as seen in Figure 21, a very thin white line near the surface. The excavation crew experienced great difficulties attempting to penetrate through the upper $-30 \mathrm{~cm}$ of T2. The stratigraphy illustrates that the densest shell material 
is at the surface and extends down through the upper $10 \mathrm{~cm}$, showing that the shell midden is evident but does not reach depths beneath Horizon 1.

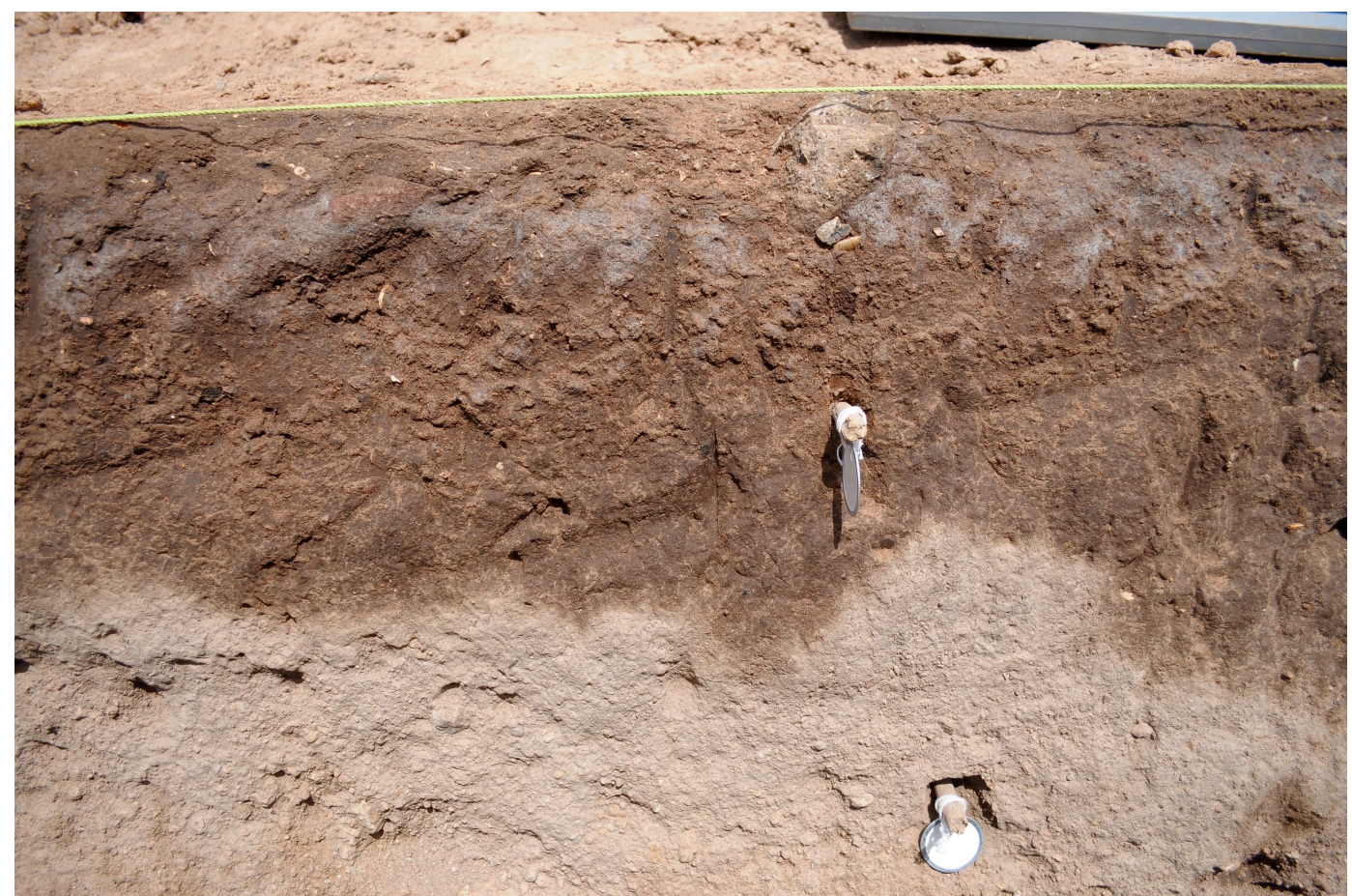

Figure 21. Decomposing calcium carbonate, attributed to chemical and physical weathering processes.

The majority of the sediment in all horizons are composed of volcanic materials (rock fragments with light and heavy minerals). Nevis's volcanic material is primarily composed of andesite and dacite (Koon Koon 2012; The University of the West Indies Seismic Research Centre 2017), and the sediment contains large amounts of volcanic rock fragments, quartz, feldspars, and hornblende found under the microscope. There are also sedimentary rock fragments mixed within each sample, and these are cemented with calcium carbonate.

During lab analysis, most time was spent breaking up the aggregates in the 
soil and discovering grain size distributions. Once the aggregates were broken up, these samples were analyzed under the microscope. One noticeable detail was that the shape of the clean sand grains is not homogeneous within one sample. Some are very angular and some pieces are very smooth and rounded. From what could be seen under the microscope, there was little shell content with some bone in $\mathrm{H} 1$, and no shell content in $\mathrm{H} 2, \mathrm{H} 3$, and $\mathrm{H} 4$.

Table 1 shows wet sieving results in which fine sediment had been separated from the sand and gravel. From these observations, I found an estimate of the silt plus clay percentages in each of the horizons. The silt plus clay content from the samples is not the same in each horizon; $\mathrm{H} 1$ contains the most silt plus clay content, then $\mathrm{H} 4$ and $\mathrm{H} 3$ contains the next most silt plus clay. The least of the four horizons silt plus clay content is $\mathrm{H} 2$ is by far. The results from the sediGraph provided a precise distribution of the silt and clay percentages. Afterwards, the data were compiled into single graphs to represent each individual horizon's course and fine sediment data (Figure 22 - 25). The most course grain material came from $\mathrm{H} 2$, as seen in (Figure 26 and 27). 
Table 1. Mud = Clay and Silt Percent of the Total Sample .

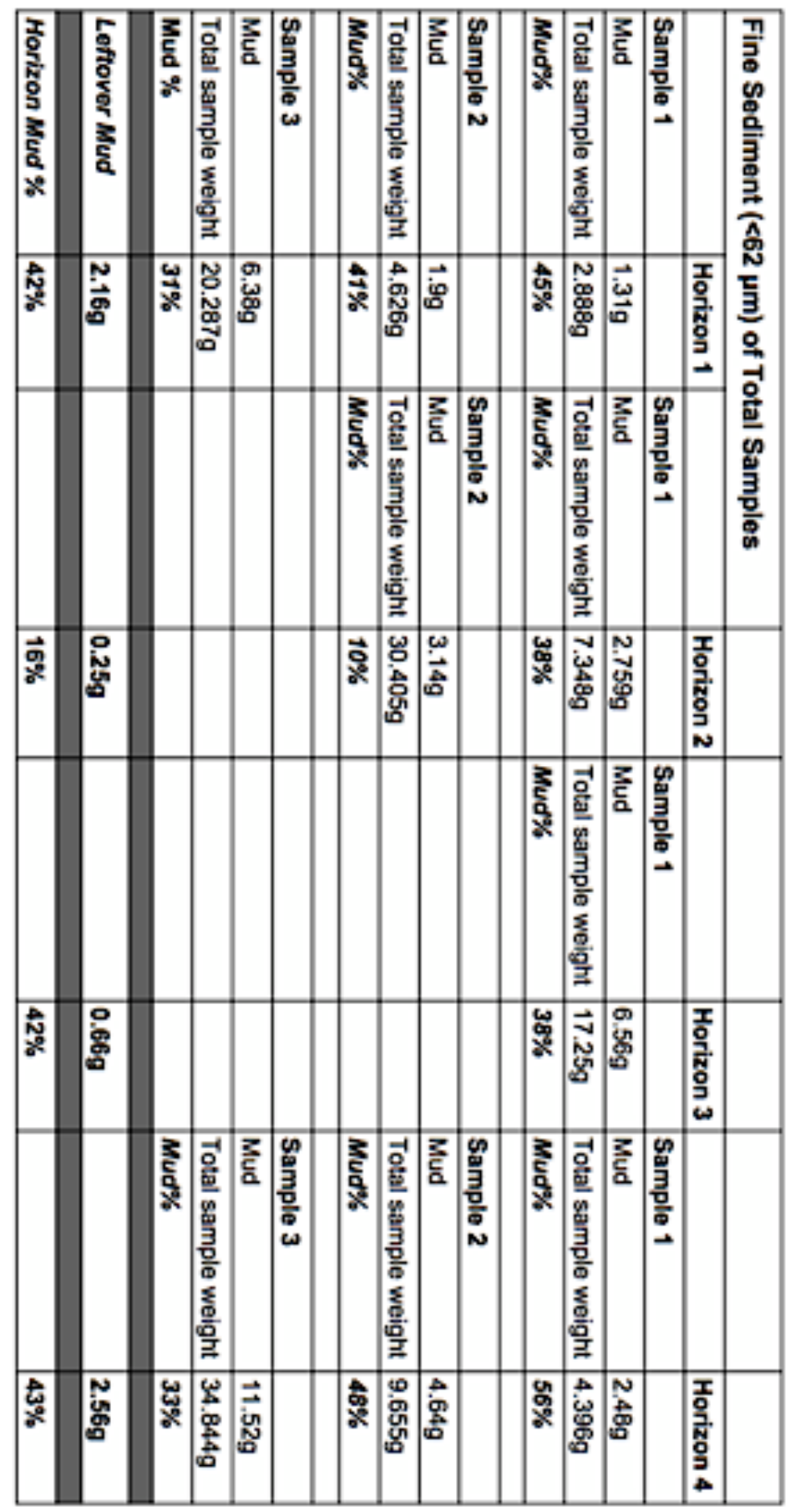

Note. Table was completed through sieve and pipette methods. 


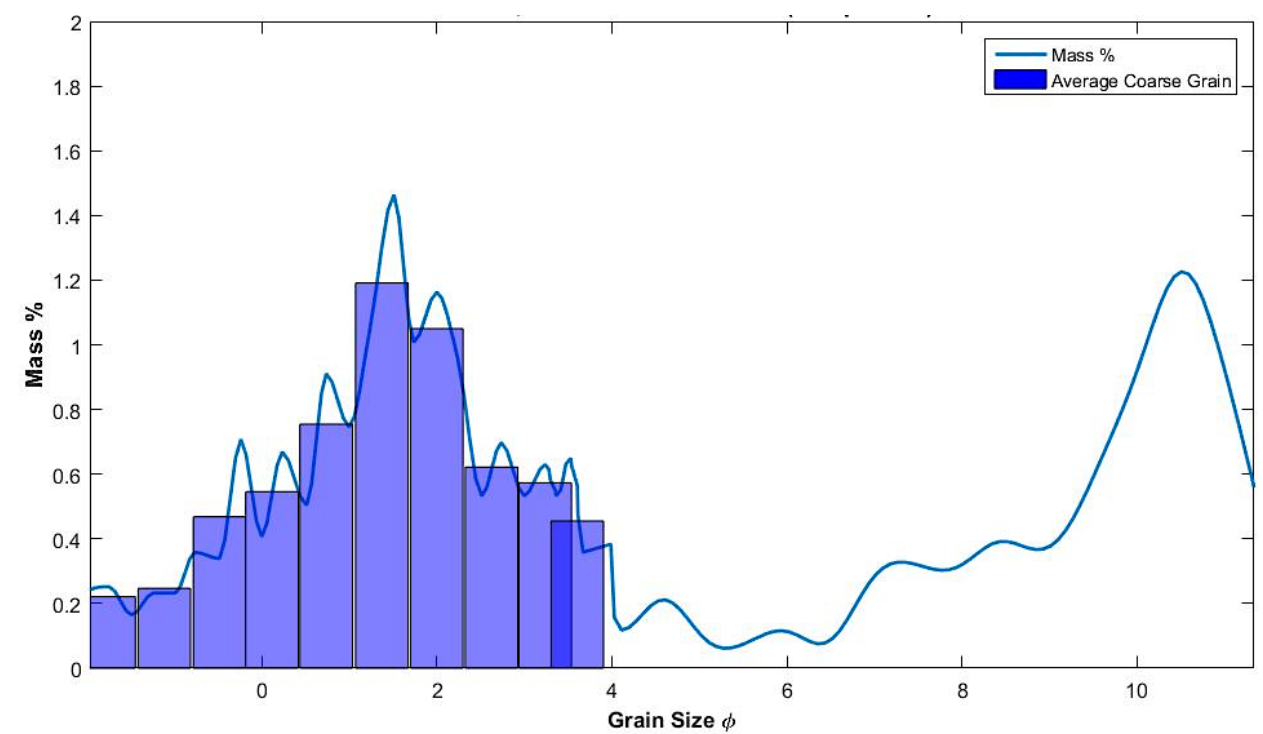

Figure 22. Horizon 1, Grain Size Distribution Interpolated (Gravel, sand, silt, and clay). The shaded histograms overlapping the coarse sand data represents the same data, but are smoothed for clarity compared to the interpolated curve.

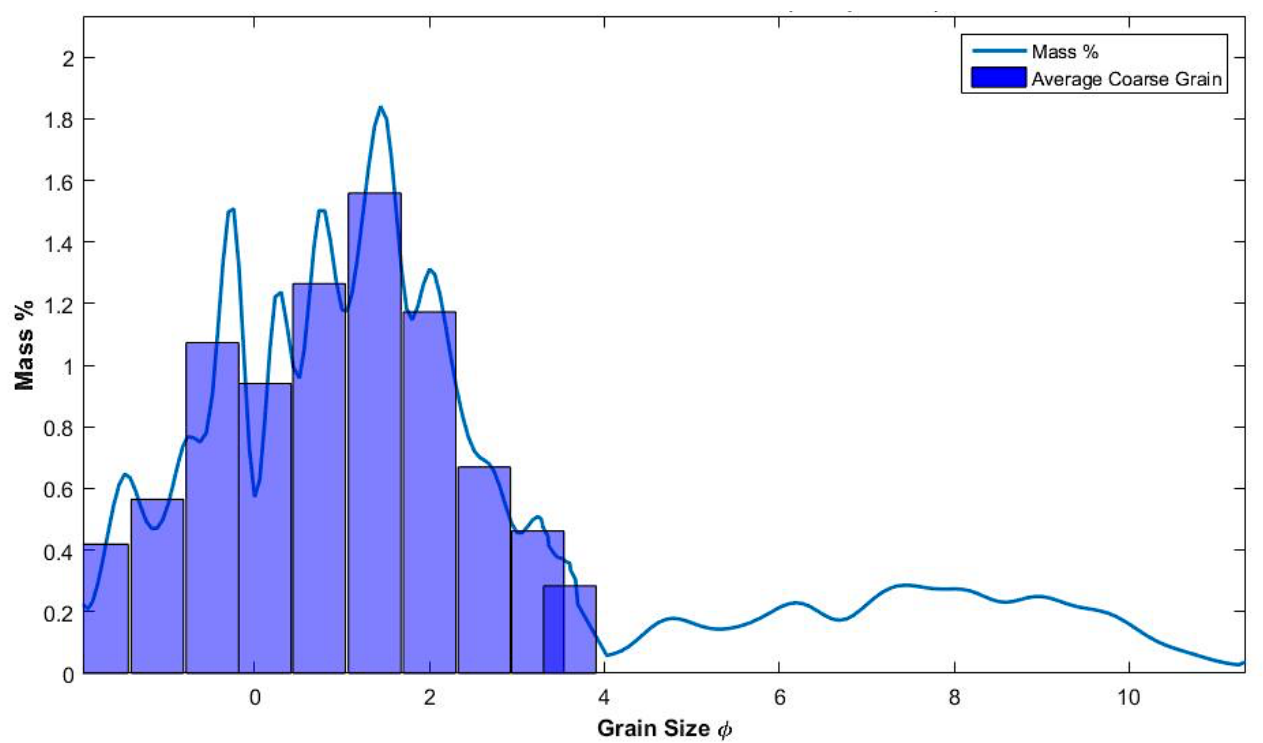

Figure 23. Horizon 2, Grain Size Distribution Interpolated (Gravel, sand, silt, and clay). 


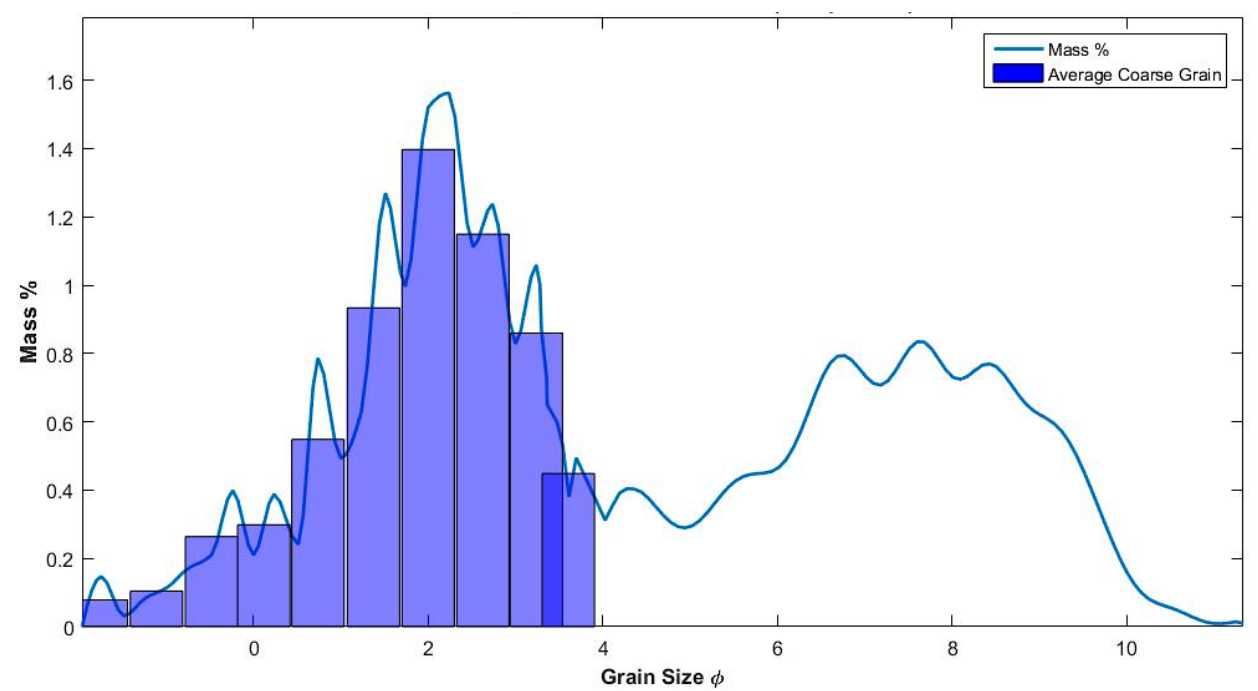

Figure 24. Horizon 3, Grain Size Distribution Interpolated (Gravel, sand, silt, and clay).

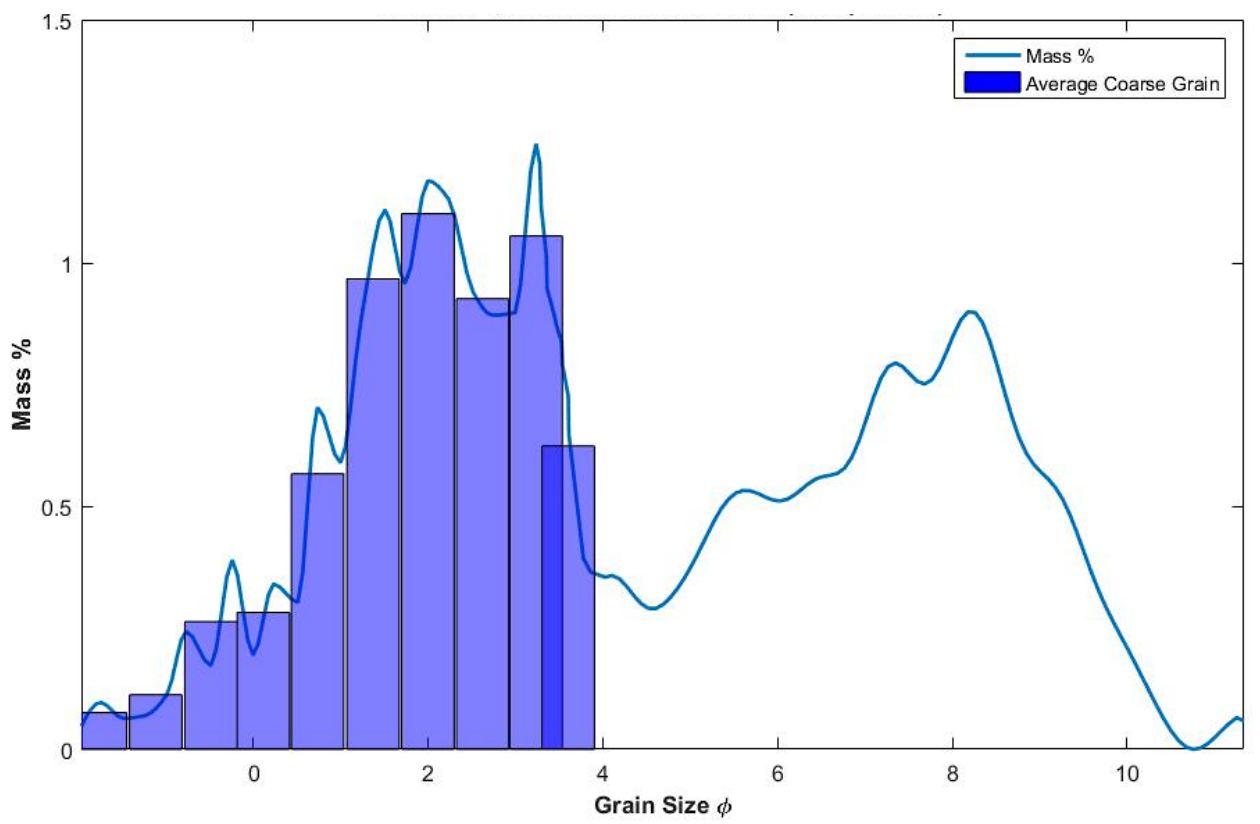

Figure 25. Horizon 4, Grain Size Distribution Interpolated (Gravel, sand, silt, and clay). 


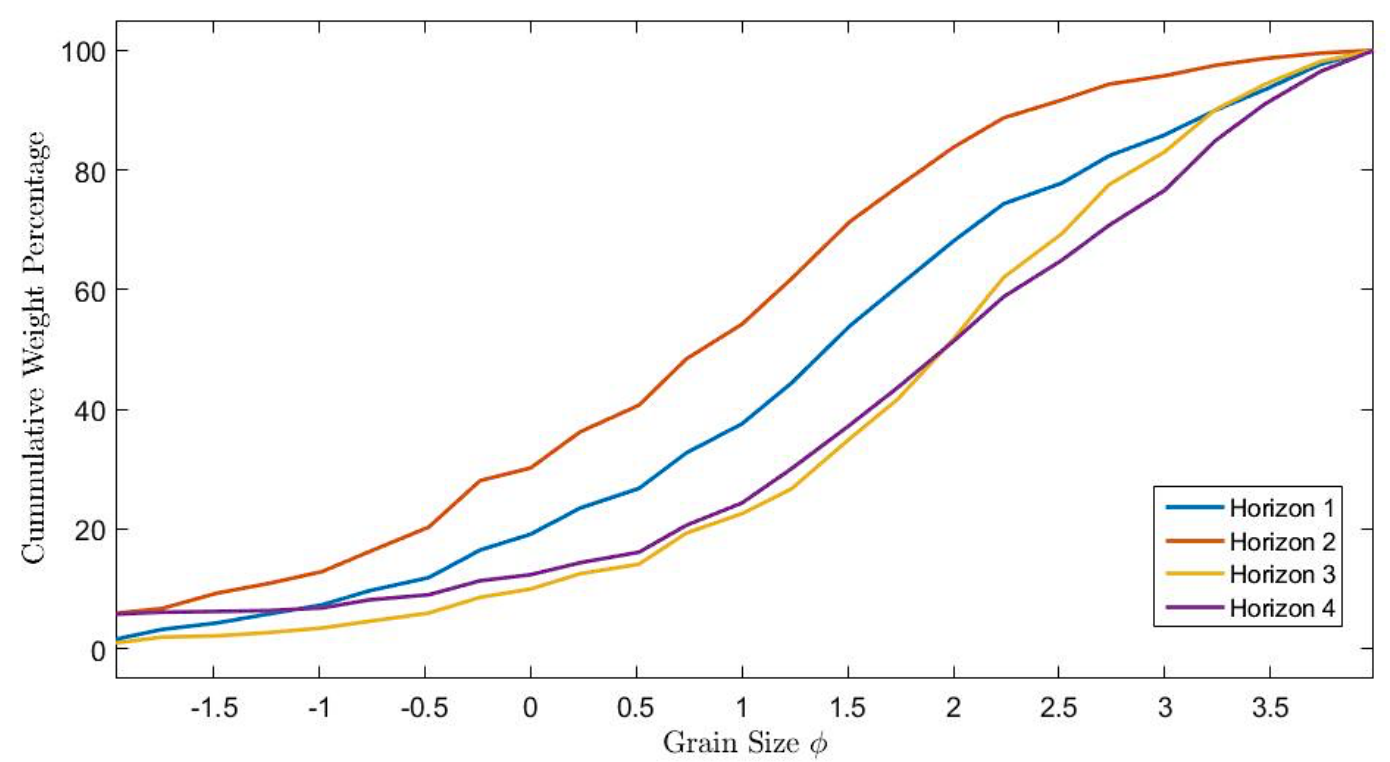

Figure 26. Cumulative curves of coarse material.

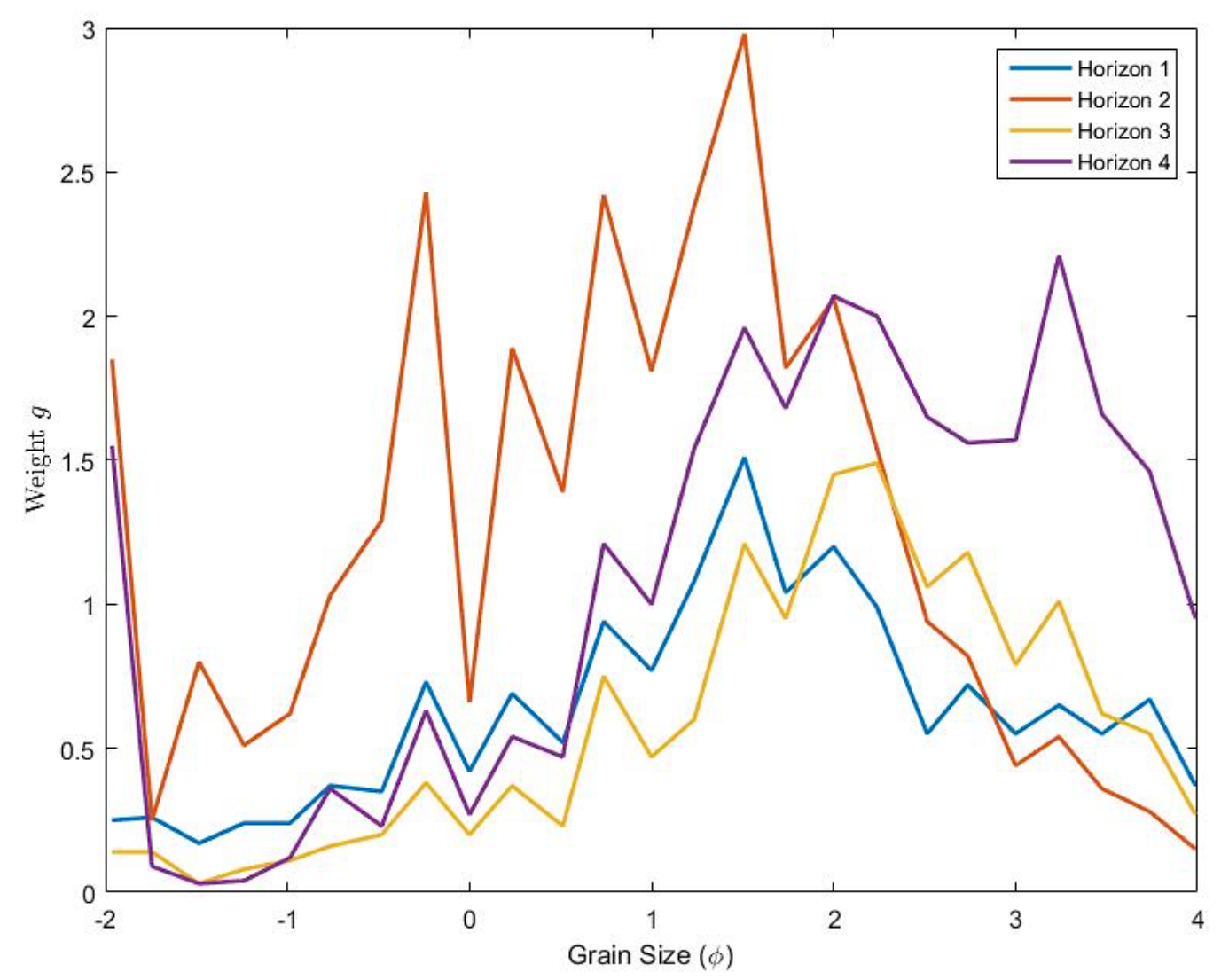

Figure 27. Line graph of coarse material. 
First, the coarse fraction of $\mathrm{H} 2$ is the coarsest, with a median size of about 0.6 $\mathrm{mm}$ (coarse sand). The median for $\mathrm{H} 1$ is about $0.35 \mathrm{~mm}$ (medium sand), and the median for both $\mathrm{H} 3$ and $\mathrm{H} 4$ is about $0.25 \mathrm{~mm}$ (close to the boundary between medium and fine sand). $\mathrm{H} 2$ and $\mathrm{H} 4$ contain more gravel than $\mathrm{H} 1$ and $\mathrm{H} 3$. Next, $\mathrm{H} 1, \mathrm{H} 3$, and $\mathrm{H} 4$ contain a lot of fine sediment (mud). Even $\mathrm{H} 2$ has more mud than one would expect to see on a beach. Finally, the mud in $\mathrm{H} 2, \mathrm{H} 3$, and $\mathrm{H} 4$ is roughly half silt and half clay (recall that the boundary is 8 phi). The mud in $\mathrm{H} 1$ contains a much higher percentage of clay.

Interpretation

Due to the eroding coastline, the shell material is inferred to be anthropogenic rather than beach debris, because the prehistoric coastline may have been as much as $200 \mathrm{~m}$ seaward of the present coastline. The combination of shells, chert debitage, and ceramic scatters indicates that this spot was a prehistoric dump site. However, this was most likely a brief dump location, not like the shell middens seen in the San Francisco Bay Area, with midden sizes matching the size of modern buildings (Uhle 1907). This finding supports the theory that the people on Nevis had much more mobile settlement patterns than those living on the larger islands.

The top $5-10 \mathrm{~cm}$ of Horizon 1 contains the only evidence of a midden. One of the major contributing factors to this observation is most likely vertical conflation, which is due to a combination of the rain $\mathrm{pH}$ and historical road compaction. Within each horizon, there are different depositional and soil forming processes. 
The anthropogenic layer $(\mathrm{H} 1)$ and $\mathrm{H} 2$ contain more course sand grains $-1 \leq \phi$ $\leq 2$, than Horizons 3 and 4 , being mostly comprised of grain sizes $1 \leq \phi \leq 4$. Smaller grains of sand are usually attributed to windblown sediments off dunes (Goldberg and Macphail 2006). The windward side of Nevis gets its name from the constant trade winds that sweep over the landscape. Horizon 4 most likely formed by stationary parent volcanic rock being filled in with windblown and some sediments of erosion from the slope above the site. Then, after these sediments were deposited, they began the pedogenic processes of decomposing in situ. The above horizons were deposited by more windblown and eroded sediment. After deposition, these horizons also underwent pedogenic processes.

As observed under the microscope, these sediment samples contain rock fragments, quartz, feldspar, and hornblende. The source of this sediment is attributed to the dacite and andesite of the volcano on Nevis. In $\mathrm{H} 4$, the red coloring is most likely attributed to iron leaching out of the parent volcanic material, while H1's dark grey color could be a result of post-Colonial effects (crop burning).

The most noticeable aspect of the stratigraphy is the change in color. These color changes portrayed in the stratigraphy were most likely pedogenic processes, and while this research was not a pedology focused research, some of the obvious processes can be described here. Horizon 1 clearly contains significantly more clay in the total sample compared to Horizon 2. From this, it can be inferred that $\mathrm{H} 1$ has experienced more intense weathering processes 
compared the horizon below $(\mathrm{H} 2)$. Horizon 1 bares a similar weathering intensity to Horizons 3 and 4. However, these observations can lead into a specific soil study (pedology - beyond previous discussion) that is beyond the scope of this sediment analysis based thesis.

The first possible horizon forming event could be caused by debris flows, which commonly contain coarse sediment with a muddy matrix. The second possibility includes sediment from floodplains being deposited in thin layers, where the sandy layers alternate with muddy ones. These layers are then usually mixed together from root and animal activity after deposition, resulting in poorly sorted mixtures of mud and sand called bioturbation. Either of these processes occur for horizons formed after colonial deforestation, because the result of clear cutting usually leads to severe erosion. However, Horizons 1 - 4 were formed before the repercussions of colonial environmental alteration. While we are seeing the effects of vertical conflation in $\mathrm{H} 1$, this is a weathering process occurring after $\mathrm{H} 1$ was deposited.

The third and most likely process is that all these layers could have been mainly sand originally, with soil-forming processes later producing silt and clay after deposition. A detail noticed under the microscope was that these horizon grains were not homogenous. That is, some grains are rounded, but mostly they are angular shaped. Angular grains are typically attributed to sediment that has not traveled as much as the rounded grains. This shows us that Horizons 1 - 4, before colonial alterations, were most likely formed in situ rather than moved by 
severe weathering alterations.

\section{Discussion}

Before this stratigraphy can be analyzed, it needs to be understood there is at least one horizon (or topsoil) missing from the strata due to physical weathering. After Europeans began to clear-cut the land and use it for sugarcane harvesting, heavy rains would wash away soil every year, requiring the Europeans to import more soil for their plantations (Meniketti 2015). These erosional patterns have been carved into the landscape and it can be observed in Figure 28, where large ghauts and small stream drainages are fanning out over the windward coast. The SJSU site is located at the mouth of a drainage basin (Figure 28). T1's lack of stratigraphy is most likely the result of the severe erosion, whereas T2 was placed about 50 meters south, avoiding the heavy drainage.

One question arising from the lab results is whether the clay percentages are significant, where our clay sources are coming from, and how they are formed. Generally, there are two different types of clays, one is a primary clay that is formed by residual "low energy" deposits, for example marine beds (Donghuai et al 2004; Goldberg and Macphail 2006). The second, however, results from secondary deposits that have been transported to a new location (Donghuai et al 2004; Goldberg and Macphail 2006). This is crucial because our previous interpretations have estimated that Horizons 1 - 4 are most likely formed in situ through pedogenic processes. 


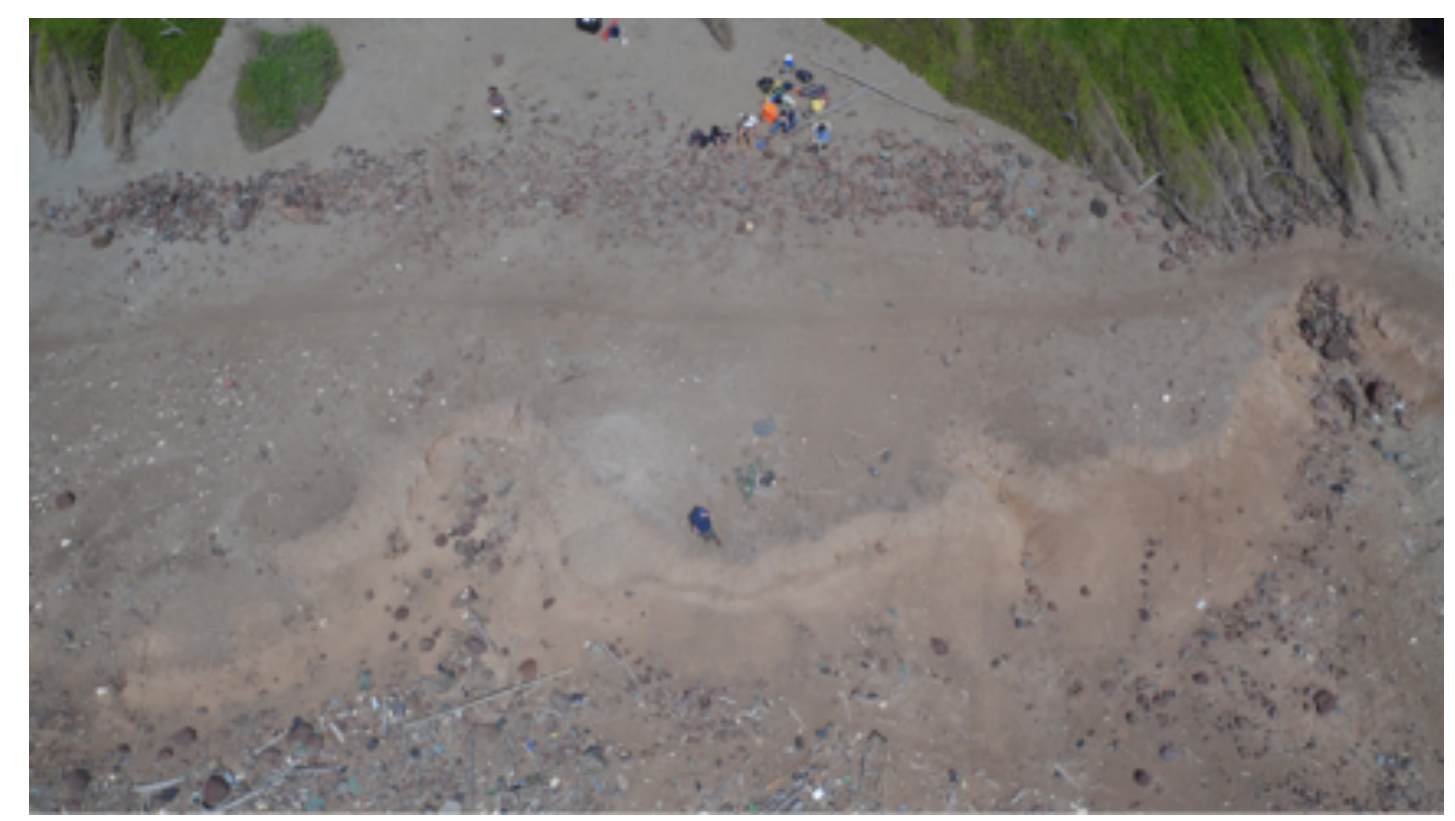

Figure 28. Drainage mouth, and accumulation of larger rocks, damming dune sand on the inland side (Photo by Tim Rodriguez and used with permission).

Clay is a fine sediment resulting partly from chemical weathering of certain rocks and minerals and in soils it can be a good proxy for climatic change (Prothero 2014). Wetter conditions are usually associated with higher clay contents caused by soil weathering, whereas drier conditions produce much less clay (Donghuai et al 2004; Goldberg and Macphail 2006). Much of the clay portrayed in $\mathrm{H} 1,3$, and 4, of the Whites Bay Beach environment is most likely due to wind-blown dust and extreme weathering conditions. We were anticipating finding much more organic material and calcium carbonate material; however, this was not the case due to the vertical conflation and accelerated decomposing processes.

Table 1 illustrates that H1's clay content source is different from that of $\mathrm{H} 3$ and $\mathrm{H} 4$, because $\mathrm{H} 2$ fine sediment content is so low. These clays are inferred to 
be primary clays forming in situ, because they have not been exposed to the surface recently. $\mathrm{H} 1$ clay origin is the result of decomposing calcium carbonate, while $\mathrm{H} 3$ and $\mathrm{H} 4$ is most likely generated from the parent material. The amount of fine sediment content in each horizon is attributed to the weathering processes that are part of the pedology formula described earlier. The dry sieve process was used to categorize grains larger than $63 \mu \mathrm{m}$, as seen previously in Figures 26 and 27.

As of today, researchers know that Nevis's pre-Colonial settlement was discontinuous after the Early Ceramic era. It has also been recently observed through datings by SJSU that Nevis was in fact inhabited from 1000 CE through $1300 \mathrm{CE}$. Although the island had been previously visited, colonial settlement of Nevis did not occur until the second wave of European exploration in the Caribbean (Wilson 2006). From colonial writings, Nevis was uninhabited at the colonization of the island in 1620s (Merrill 1958; Oldmixon 1708; Wilson 2006), but there have been mixed observations stating the island was inhabited and or deserted at different times.

Trade routes can disperse more than just material goods. Most likely, the first wave of exploration which took place in the Greater Antilles began a trend of disease which could have spread down to the smaller islands of the Lesser Antilles.This possibly explains the question of why populations were decreasing leading up to the period of European settlement (Wilson 2006). Also, after a few accounts of genocide, people could have heard through travels that Europeans 
were a threat, and over time people retreated to gather on larger islands to defend themselves from slavery (Merrill 1958; Wilson 2006). But the question remains as to what exactly caused the discontinuous settlement of these islanders when the island was thriving in the beginnings of the Late Ceramic.

From the observations of the later years of the Early Ceramic sites, and the early years of the Late Ceramic sites on Nevis, there was a trend toward population growth. As discussed previously, a popular observation among scholars in this field includes that there was an abrupt social change which caused the transition from the Early Ceramic period to the Late Ceramic period. The research question that drove this thesis however, was whether sediment analysis of a shell midden could identify an environmental change on Nevis, and possibly influencing settlement patterns. However, from the results of T2, I detected there was distinct environmental changes earlier in Nevis's history that could have influenced change in settlement. The cause of this change could not be determined by sediment analysis solely because the original topsoil was missing, and further soil analysis is needed to further answer this question.

The theory regarding Nevis's climatic past can be illustrated in the stratigraphy from T2. As discussed earlier, researchers have suggested there was a climatic change in the Caribbean and that the region was drier from 3,200 to 1,000 years ago (Wilson 2006; Siegel et al. 2015; Keegan 2017). Wilson's (2006) wood taxonomy study identified nine different types of wood species typically found in a dry tropical forest environment that are not exhibited today on 
Nevis. T2 stratigraphy illustrates higher clay contents in $\mathrm{H} 3$ and $\mathrm{H} 4$ (wet environment) and significantly less clay in $\mathrm{H} 2$ (illustrating a short period of the drier climate). Then $\mathrm{H} 1$ returns to higher clay content about 1,000 years ago illustrating the wet climate we currently experience on Nevis.

There were nine different types of wood found through floatation tests by Wilson (2006). Most of these woods had not been previously recorded as native species on Nevis. These wood taxonomies relate to land use and climate/vegetation type (Wilson 2006). The types of wood analyzed represent a landscape of tropical dry and moist forest, depending on ecology and topographic conditions at the time. This analysis relates to the weathering process I have encountered in the stratigraphy and the fine sediment distributions in the lab. The climate in the Caribbean has become more moist overtime; when it was once drier (Wilson 2006).

There are still questions that remain regarding this environmental change before Nevis's pre-Colonial era. As of today, we know how much clay is in each horizon and we can clearly see there is an environmental change from $\mathrm{H} 3$ to $\mathrm{H} 2$, and from $\mathrm{H} 2$ to $\mathrm{H} 1$, but future research should analyze clay mineralogy to test wether clays were in fact formed under pedogenic processes through weathering. We have concluded from the data that there are multiple weathering processes occurring, but the exact process is unknown. Another crucial question includes, how old is $\mathrm{H} 2$ ? This information could be beneficial, because we currently are only dating $\mathrm{H} 2$ by comparison of our tables to the climate data, 
Wilson's (2006) wood taxonomies, and relatively dating skeletal remains found at certain depths. However, it would be much more efficient to investigate the actual age of $\mathrm{H} 2$ before we can determine if past climate data matches our tables from the midden data. 


\section{CHAPTER 6: CONCLUSIONS}

The coastlines of Nevis are difficult to interpret due to the mass amounts of erosion and industrial era impacts of sugar cultivation. The main objectives of this thesis were to explore the application of sediment analysis and landscape surveys of the Whites Bay midden site and to determine if there was any sort of environmental change that could have influenced a cultural change leading to the Late Ceramic era.

In the Findings chapter, I described how the results of each horizon contained different amounts of clay content. From the observations, I found that $\mathrm{H} 1$ contains the most silt plus clay content, and $\mathrm{H} 4$ and $\mathrm{H} 3$ contain the next most silt plus clay content. The least silt plus clay content is located in $\mathrm{H} 2$, which could correlate with the climatic changes I discussed matching other works, including Wilson's (2006) wood taxonomies, and recent climate surveys. The climate change seen in the stratigraphy could align with the brief change in climate discussed by other researchers; however, further research specifically in pedology and mineralogy of the clay, would be necessary for more specific interpretations.

From the results, I also describe how the most course grain material came from $\mathrm{H} 2$ with a median $0.6 \mathrm{~mm}$ (coarse sand), and the mud in $\mathrm{H} 2, \mathrm{H} 3$, and $\mathrm{H} 4$ is roughly half silt and half clay. Juxtaposed to the striking change in color from each horizon, I interpreted these results as a clear change in climate from $\mathrm{H} 3$ to $H 2$, and from $\mathrm{H} 2$ to $H 1$, with different depositional processes. This inference 
provides a possible mechanism for the cultural change described after $1000 \mathrm{CE}$. The exact relationship between cultures of pre-Colonial Nevis and their environments is not yet known. However, further pedological analysis must be conducted for more information. My thesis concludes its findings with further emphasis that if coastal sites are not examined soon, then these sites will become more difficult to reconstruct due to erosion. With the elimination of these sites, questions regarding pre-Colonial Caribbean culture could never be answered.

Future research should analyze clay mineralogy to test the idea if clays were in fact formed under pedogenic processes through weathering. From the data, I have concluded there are multiple weathering processes occurring, but the exact process is unknown. This direction could begin to explain what the exact environmental change is that is being observed in the stratigraphy. I am confident that my research has provided the evidence that there was in fact an environmental change from $\mathrm{H} 3$ to $\mathrm{H} 2$, and $\mathrm{H} 2$ to $\mathrm{H} 1$. However, another gap that still remains in this research includes how old $\mathrm{H} 2$ is. This information would be crucial, because we currently are only dating $\mathrm{H} 2$ by relative comparison to Wilson's (2006) data.

The key objectives of this thesis were to better understand the prehistoric environment of Nevis by integrating archaeological and geological methodologies. Archaeologists have always incorporated basic theories of earth science, but in recent decades, the current archaeological field has included 
methods and results that are more precise. Future researchers can incorporate and build from this research to further investigate how Nevis's environment influenced indigenous Caribbean culture. If these sites are not examined soon, we may never truly understand the prehistory of the Caribbean because future data will be lost due to the active coastal erosion and potential sea level rise. There are still many questions regarding site forming processes and how they influenced settlement patterns in pre-Colonial Nevis that have yet to be answered. It is crucial for future archaeologists to explore and expand the knowledge of the prehistoric Carib peoples, including their relationship with Nevis's environment. 


\section{LITURATURE CITED}

Allaire, Louis 1997 Indigenous Peoples of the Caribbean. Samuel M. Wilson. University Press of Florida: Tallahassee, Florida.

2008 The Cambridge History of the Native Peoples of the Americas. South America Vol. III. Cambridge University Press, Cambridge.

Ambrose, W. R.

1967 Archaeology and Shell Middens. Volume II, No 3. Archaeology and Physical Anthropology in Oceania 2(3):169-187.

Bird, Eric 2011 Coastal Geomorphology: An Introduction, 2nd Edition. John Wiley and Sons LTD, England.

British Society for Geomorphology 2017 What is Geomorphology? http://www.geomorphology.org.uk/whatgeomorphology-0 accessed Jan 2017.

Bouysse, P., Westercamp, D., Andreieff, P. 1990 The Lesser Antilles island arc. Proceedings of the Ocean Drilling Program. Quaternary Research 25 (3): 369-379.

Crumley, Carole L., and Alf Hornborg 2007 The World System and the Earth System. Walnut Creek: Left Coast Press.

David, Bruno, and Julian Thomas, eds. 2008 Handbook of Landscape Archaeology. Walnut Creek: Left Coast Press.

Davis, Dave D., and Christopher Goodwin 1990 Island Carib Origins: Evidence and Nonevidence. American Antiquity 55(1): 37-48.

Fitzpatrick, Scott M. 2006 A Critical Approach to Carbon Dating in the Caribbean: Using Chronometric Hygiene to Evaluate Chronological Control and Prehistoric Settlement. Society for American Archaeology 17(4): 389-418. 
Geological Society of London

2017 Plate Tectonics: Plate Margins, Oceanic vs Oceanic. https://www.geolsoc.org.uk/Plate-Tectonics/Chap3-PlateMargins/Convergent/Oceanic-oceanic-collision accessed Jan 2017.

Goldberg, Paul, Vance Holliday, and C. Reid Ferring, ed. 2001 Earth Sciences and Archaeology. Kluwer Academic/Plenum Publishers, New York.

Goldberg, Paul and Richard Macphail 2006 Practical and Theoretical Geoarchaeology. Malden, Blackwell.

Hassan, Fekri A.

1978 Sediments in Archaeology: Methods and Implications for

Paleoenvironmental and Cultural Analysis. Journal of Field Archaeology 5(2): 197-213.

1979 The Geologist and Archaeology. Society for American Archaeology 44(2): 267-270.

Higuera-Gundy, A., Brenner, M., Hodell, D.A., Curtis, J.H., Leyden, B.W., and Binford, M.W.

1999 A 10,300 14C yr Record of Climate and Vegetation Change from Haiti. Quaternary Research 52 (2): 159-170.

Hodell, D.A., Curtis, J.H., Jones, G.A., Higuera-Gundy, A., Brenner, M., and Binford, M.W.

1991 Reconstruction of Caribbean Climate Change Over the Past 10,500 years. Nature. 352: 790-793.

Hubbard, Lucius Lee

1931 Did Columbus discover the island's Antigua and St. Martin? The University of Michigan, Michigan.

Jenny, Hans

1941 Factors of Soil Formation: A System of Quantitative Pedology. Dover Publications, New York.

Keegan, William F. 1994 West Indian Archaeology: 1 Overview and Foragers. Journal of Archaeological Research 2(3): 255-284.

2000 West Indian Archaeology: 3 Ceramic Age. Journal of Archaeological Research 8(2): 135-167. 
Keegan, William F., and Corinne L. Hofman 2017 The Caribbean Before Columbus. Oxford University Press, New York.

Keith, Chris 2014 The Excavation and Analysis of Prehistoric Caribbean Remains: A Bioarchaeology Case Study of a Prehistoric Female From Nevis, West Indies. M.A. Thesis, Anthropology Department, San Jose State University.

Koon Koon, Randy R.

2012 Geothermal Energy Prospecting for the Caribbean Islands of Nevis and Montserrat. GHC Bulletin, Department of Physics, The University of the West Indies St. Augustine Trinidad.

Kraft, J.C., G. Rapp, Jr. and S.F. Aschenbrenner 1975 Late Holocene Paleogeography of the Coastal Plain of the Gulf of Messinia, Greece, and its relationship to Archaeological Settings and Coastal Change. Geological Society of America Bulletin 86: 1191-1208.

Kvamme, Kenneth L. 2003 Geophysical Surveys as Landscape Archaeology. American Antiquity 68 (3): 435-457.

Meniketti, Marco 2006 Sugar Mills, Technology, and Environmental Change: A Case Study of Colonial Agro-Industrial Development in the Caribbean. The Journal of the Society for Industrial Archaeology 32(1): 53-80.

2015 Sugar Cane Capitalism and Environmental Transformation: An Archaeology of Colonial Nevis, West Indies. The University of Alabama Press, Tuscaloosa.

Merrill, Gordon C. 1958 The Historical Geography of St. Kitts and Nevis, The West Indies. Instituto Panamerican de Geografia e Historia, Mexico. 
Morris, Elaine L., Andrew Crosby, Roger Leech, Tessa Machling, Peter Bellamy, JL Heathcote, Alison Locker, Bruce Williams.

2000 The Nevis Heritage Project: Interim Report. Department of Archaeology University of Southampton, UK.

2001 The Nevis Heritage Project: Interim Report. Department of Archaeology University of Southampton, UK.

2002 The Nevis Heritage Project: Interim Report. Department of Archaeology University of Southampton, UK.

Nicholson, Desmond V.

1975 Precolumbian Seafaring Capabilities in the Lesser Antilles. Paper presented at the 6th International Congress for the Study of Pre-Columbian Cultures of the Lesser Antilles, Guadeloupe.

Oldmixon, John

1708 The British Empire in America, British Colonies on The Continent and Islands of America 2: 195-219.

Prothero, Donald R. and Fred Schwab

2014 Sedimentary Geology: An Introduction to Sedimentary Rocks and Stratigraphy. W.H. Freeman and Company, New York.

Rapp, George and Christopher L. Hill 2006 Geoarchaeology: The Earth-Science Approach to Archaeological Interpret. Yale University Press, New Haven.

Righter, Elizabeth 1991 Importance of Soil Sampling and Analysis. Proceedings of the 13th Annual International Congress for the Study of Pre-Columbian Cultures of the Lesser Antilles, Guadeloupe.

Roksandic, Mirjana., William Mark Buhay, Yadira Chinique de Armas, Roberto Rodriguez Suarez, Matthew C Peros, Ivan Roksandic, Stephanie Mowat, Luis M Viera, Carlos Arredondo, Antonio Marinez Fuentes, David Gray Smith 2015 Radiocarbon and Stratigraphic Chronology of Canimar Abajo, Matanzas, Cuba. Arizona Board of Regents on behalf of the University of Arizona 57(5): 755-763. 
Rouse, Irving 1951 Areas and Periods of Culture in the Greater Antilles. Southwestern Journal of Anthropology 7(3): 248-265.

1961 Archaeology in Lowland South America and the Caribbean. Society for American Archaeology 27(1): 56-62.

1964 Prehistory of the West Indies. Science, New Series. American Association for the Advancement of Science 144 (3618): 499-513.

1969 Early Man in the West Indies. Scientific American 221(5).

1977 Pattern and Process in West Indian Archaeology. World Archaeology 9(1): 1-11.

Ruppe, Reynold J.

1979 Sea-Level Rise and Caribbean Prehistory. Paper presented at the 6th International Congress for the Study of Pre-Columbian Cultures of the Lesser Antilles, Guadeloupe.

Siegel, Peter E., John G. Jones, Deborah M. Pearsall, Nicholas P. Dunning, Pat Farrell, Neil A. Duncan, Jason H. Curtis, Sushant K. Singh. 2015 Paleoenvironmental Evidence for First Human Colonization of the Eastern Caribbean. Quaternary Science Reviews 129: 275-295.

Sleight, Frederick W.

1965 Certain Environmental Considerations in West Indian Archaeology. Society for American Archaeology 31(2): 226-231.

The University of the West Indies Seismic Research Centre Nevis Geological Profile Report. http://uwiseismic.com/Downloads/nevis4website.pdf, accessed Jan 2017.

Uhle, Max 1907 The Emeryville Shellmound. University Press: Berkeley, California.

United States Geological Survey Geological Provinces Caribbean Islands Map. https://pubs.usgs.gov/ of/1997/ofr-97-470/OF97-470K/spatial/pdf/caribbean.pdf, accessed Jan 2017. 
Watters, David R.

1997 Maritime Trade in the Prehistoric Eastern Caribbean. In The Indigenous People of the Caribbean. Samuel Wilson, ed. Pp. 88-99. University Press of Florida: Tallahassee, Florida.

Watters and Donahue 1985 Geoarchaeological Research on Antigua, Montserrat, and Barbuda. Paper presented at the 6th International Congress for the Study of PreColumbian Cultures of the Lesser Antilles, Guadeloupe.

Williams, Jeffress S.

2009 Chapter C. Past, Present, and Future Sea Level Rise and Effects on Coasts Under Changing Global Climate. Scientific Investigations Report, U.S. Geological Survey.

Wilson, Samuel M.

1989 The Prehistoric Settlement Pattern of Nevis, West Indies. Journal of Field Archaeology 16(4): 427-450.

1993 The Cultural Mosaic of the Indigenous Caribbean. Proceeding of the British Academy 81: 37-66.

1997 The Indigenous People of the Caribbean. University Press of Florida Tallahassee.

2006 The Prehistory of Nevis, a Small Island in the Lesser Antilles. Yale University Publications, New Haven.

2007 Archaeology of the Caribbean. Cambridge University Press, New York. 